\title{
HIV-1-encoded antisense RNA suppresses viral replication for a prolonged period
}

\author{
Mie Kobayashi-Ishihara', Makoto Yamagishi ${ }^{1}$, Takuma Hara', Yuka Matsuda ${ }^{1}$, Ryutaro Takahashi $^{1}$, Ariko Miyake², \\ Kazumi Nakano ${ }^{1}$, Tadanori Yamochi ${ }^{1}$, Takaomi Ishida ${ }^{3}$ and Toshiki Watanabe ${ }^{1 *}$
}

\begin{abstract}
Background: Recent evidence proposes a novel concept that mammalian natural antisense RNAs play important roles in cellular homeostasis by regulating the expression of several genes. Identification and characterization of retroviral antisense RNA would provide new insights into mechanisms of replication and pathogenesis. HIV-1 encoded-antisense RNAs have been reported, although their structures and functions remain to be studied. We have tried to identify and characterize antisense RNAs of HIV-1 and their function in viral infection.

Results: Characterization of transcripts of HEK293T cells that were transiently transfected with an expression plasmid with HIV-1 NL4-3 $_{2}$ DNA in the antisense orientation showed that various antisense transcripts can be expressed. By screening and characterizing antisense RNAs in HIV-1 NL4-3 $_{3}$-infected cells, we defined the primary structure of a major form of HIV-1 antisense RNAs, which corresponds to a variant of previously reported ASP mRNA. This $2.6 \mathrm{~kb}$ RNA was transcribed from the U3 region of the 3' LTR and terminated at the env region in acutely or chronically infected cell lines and acutely infected human peripheral blood mononuclear cells. Reporter assays clearly demonstrated that the HIV-1 LTR harbours promoter activity in the reverse orientation. Mutation analyses suggested the involvement of NF-KB binding sites in the regulation of antisense transcription. The antisense RNA was localized in the nuclei of the infected cells. The expression of this antisense RNA suppressed HIV-1 replication for more than one month. Furthermore, the specific knockdown of this antisense RNA enhanced HIV-1 gene expression and replication.

Conclusions: The results of the present study identified an accurate structure of the major form of antisense RNAs

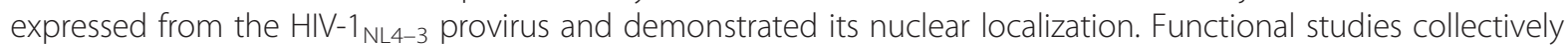
demonstrated a new role of the antisense RNA in viral replication. Thus, we suggest a novel viral mechanism that self-limits HIV-1 replication and provides new insight into the viral life cycle.
\end{abstract}

\section{Background}

The genome of HIV-1 is about $9 \mathrm{~kb}$ with complex pathogenic mechanisms. HIV-1 encodes nine viral proteins, which have multiple functions in molecular events such as entry, integration, and viral gene expression, as well as the regulation of host molecular processes [1-3]. However, there still remain unanswered questions about the mechanisms of HIV-1 infection and pathogenesis despite advances in the knowledge of many diverse viral functions. For example, mechanisms for viral latency and

\footnotetext{
* Correspondence: tnabe@k.u-tokyo.ac.jp

'Laboratory of Tumor Cell Biology, Department of Medical Genome Sciences, Graduate School of Frontier Sciences, The University of Tokyo, 4-6-1

Shirokanedai, Minato-ku, Tokyo 1088639, Japan

Full list of author information is available at the end of the article
}

reactivation have not been fully elucidated, and several events have been suggested to be involved in viral latency, including epigenetic reprogramming and modulated expressions of host factors [4-6].

Several researchers have embarked on studies to identify HIV-1 antisense RNAs (asRNAs) [7-11]. Using computational analysis, Miller predicted the existence of a novel gene in the antisense strand of HIV-1, which encodes ASP by a well-conserved open reading frame among many strains of HIV-1 [7]. Subsequently, the ASP mRNA was identified as a 2242 bp transcript covering the region between nucleotide positions 9608 and 7367 of the HXB2 strain in acutely infected A3.01 cells [8]. However, the primary structure and functions of HIV- 1 asRNAs have not

\section{Biomed Central}


been fully clarified, although many researchers have proposed the potential importance of the asRNAs [9,12-20].

Other retroviral asRNAs have also been studied. In HTLV-1-infected T-cells, the HBZ RNA is expressed from the antisense strand of the HTLV-1 provirus. HBZ has been reported to be involved in the regulation of sense transcription and leukemogenesis by HTLV-1 [21-26]. Furthermore, feline immunodeficiency virus and Friend and Moloney murine leukemia virus have also been suggested to express antisense transcripts $[27,28]$. In addition, Ty1 retrotransposon was shown to express three types of asRNAs, which can regulate the Ty1 copy numbers in yeasts [29].

Recent studies including the FANTOM3 mouse transcriptome sequencing consortium identified natural antisense transcripts for more than $70 \%$ of transcription units (TUs), most of which represent non-protein-coding RNAs [30,31]. The existence and functional importance of asRNAs in various species have also been elucidated [31-34]. Various natural antisense RNAs (NATs) play important roles in the regulation of gene expression through diverse molecular mechanisms, such as X-chromosome inactivation (Tsix), genomic imprinting (Air), and trans-acting regulation (HOTAIR and ANRIL) of its sense strand expression [31,35-40]. Furthermore, abnormal expression of asRNAs is reported to be one of the risk factors in some diseases such as $\alpha$ thalassemia, cardiac diseases, and Alzheimer's disease $[37,41,42]$. Thus, the transcriptional control of asRNAs is considered to be a potential target for the development of new treatment strategies as well as the prevention of diseases.

Consequently, the identification and delineation of the precise primary structure and functions of HIV-1 asRNAs is urgently needed, because that information may provide new insights into the pathogenic mechanisms of HIV-1. In the present study, we identified an apparent major form of asRNAs, $A S P-L$, in HIV-1 $1_{\text {NL4-3 }}$ and $\mathrm{HIV}_{\text {IIIB }}$ infected cells. The results demonstrated that the $A S P-L$ is localized in the nucleus and has a potential to negatively regulate HIV-1 replication. These findings suggest a novel mechanism that may play a role in the self-limiting replication of HIV-1.

\section{Results}

\section{Mapping of potential antisense RNAs from HIV-1 proviral DNA}

Specific detection and identification of antisense transcripts of HIV-1 is difficult because of the presence of several sense transcripts $[8,11]$. Thus, we first attempted to characterize the candidate transcripts from the antisense strand of HIV DNA. We studied the transcripts in HEK293T cells that were transiently transfected with an expression plasmid, pME18S-asHIV, which contains the gag to nef region of HIV-1 ${ }_{\mathrm{NL} 4-3}$ DNA in the antisense orientation was positioned between the RSV promoter and the SV40 poly (A) sites (Figure 1A). Total RNAs were extracted from the transfected cells and comprehensively analyzed by Northern blots using region specific probes against the HIV-1 p1-p5 regions (Figure 1B). Four major bands were detected that may represent potential antisense transcripts as shown in Figure 1B. We named these four bands I to IV based on their apparent molecular sizes. Transcript I is apparently a $10 \mathrm{~kb}$ genome-length transcript, and transcript II is a $5.5 \mathrm{~kb}$ transcript detected by $\mathrm{p} 2-\mathrm{p} 5$ probes. Transcript III appears to be a group of transcripts of 3$4 \mathrm{~kb}$ in size that hybridized with all probes except the $\mathrm{p} 1$ probe. Transcript IV is a $2 \mathrm{~kb}$ transcript that hybridized with $\mathrm{p} 3, \mathrm{p} 4$, and $\mathrm{p} 5$ probes, with a stronger signal to the $\mathrm{p} 5$ probe. Taken together, the results indicate that various transcripts can be transcribed from the antisense strand of HIV-1 DNA. Among these transcripts, those grouped in transcript III are expressed at high levels.

To characterize the detailed structure of these transcripts, we next performed RT-PCR analyses and 3' RACE PCRs, and determined the spliced sites and the transcription termination sites (Additional file 1: Figure S1and Additional file 2: Figure S2). Nucleotide sequence analyses of the amplified products revealed three kinds of spliced transcripts and four polyadenylation sites, suggesting seven kinds of potential asRNAs (Figure 1C). They are described as follow: Transcript I, a transcript with genome-length; Transcript II, a $5.5 \mathrm{~kb}$ transcript covering the nucleotide sequence from 9102 to 4885 of HIV-1 $1_{\text {NL4-3 }}$-sense DNA [GenBank: M19921.2] which corresponds to ASP mRNA reported by Landry et al. [11]; Transcripts III-i and III-ii, $4 \mathrm{~kb}$ transcripts terminating at the SV40 poly(A) sites in the vector; Transcript III-iii, a $3 \mathrm{~kb}$ transcript ranging from the nef to env regions of the sense strand (See Additional file 1: Figure S1. Determination of transcript III-iii); and Transcript IV, two transcripts terminating at the SV40 poly (A) sites (transcript IV-i) or at 7338 bp (transcript IV-ii) which corresponds to ASP mRNA reported by Michael et al. [8].

\section{Detection of HIV-1 antisense RNAs in infected cells}

Based on the above results, we next examined whether the putative asRNAs are expressed in HIV-1-infected cells. Previous reports have documented that endogenous priming in the step of cDNA synthesis prevents strand-specific RT-PCR for analysis of intragenic asRNAs [11,43]. To eliminate the nonspecific amplification products, we utilized the strand-specific RT-PCR method (Figure 2A) [11,23], using MAGIC-5A cells infected with HIV-1 [44]. Antisense-specific RT-PCR was performed on five regions, R1-R5. Viral asRNAs were detected in all regions analyzed in MAGIC-5A infected with HIV-1 $1_{\mathrm{NL4}-3}$ (Figure 2B). However, no cDNA was amplified that corresponds to a spliced form of asRNA, including transcripts III-i, III-ii, and IV-i (Additional file 2: Figure S2). These results indicated that 


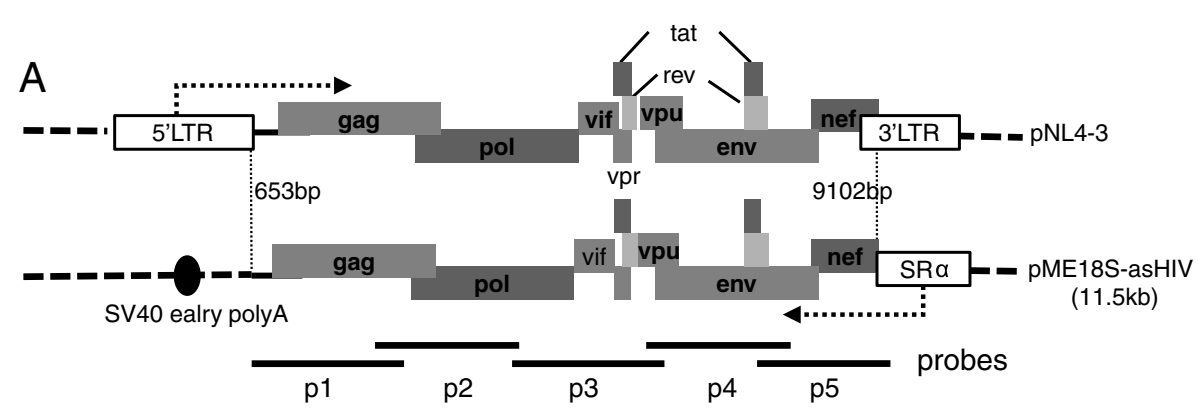

B
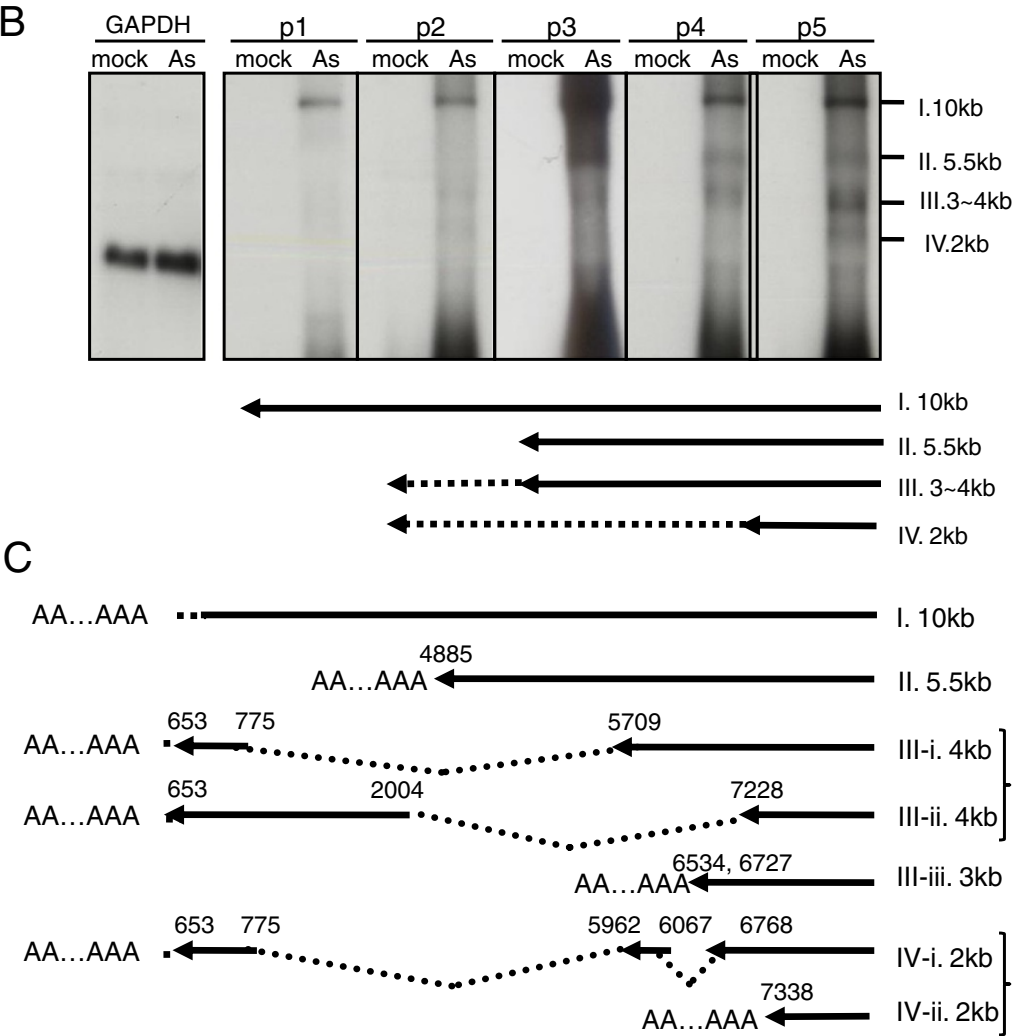

Figure 1 Mapping of the potential antisense RNAs transcribed from the HIV-1 proviral DNA. (A) A schematic diagram of the pME18S-

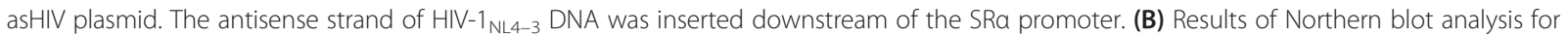
the detection of the RNAs from pME18S-asHIV. HEK293T cells were transfected with pME18S-asHIV or a mock vector, pME18S. Total RNA samples isolated from these cells were analyzed with region-specific probes described in A (p1-p5). GAPDH RNA was used as a loading control. The arrows described below are the positions of potential transcripts I-IV as described in the results. 'Mock' stands for the RNA sample extracted from cells transfected with a mock vector. 'As' stands for RNA samples extracted from cells transfected with pME18S-asHIV. (C) The summary of the transcription patterns in PME18S-asHIV-transfected cells. Spliced variants derived from antisense HIV-1 were identified by RT-PCR, and termination sites were determined by the 3' RACE methods described in Additional file 1: Figure S1 and Additional file 2: Figure S2. Nucleotide numbering corresponds to the sense strand of HIV-1 ${ }_{\text {NL4-3 }}$-DNA.

the antisense transcripts cover the region between $657 \mathrm{bp}$ and $9094 \mathrm{bp}$ and are unspliced forms in HIV-1 infected cells.

\section{Identification of a novel variant of ASP RNA, ASP-L}

The above results suggested that asRNAs of HIV-1, including transcripts I, II, III-iii and IV-ii, can be expressed in HIV-1-infected cells. To confirm the existence of these potential asRNAs and determine their primary structures, we next studied HIV-1 asRNAs in HIV-1-infected MAGIC-5A by 3' RACE PCR analyses. Using the primer $\mathrm{p} 4 \mathrm{R}$ that is located in the ASP open reading frame (ORF), a PCR product with an apparent molecular size of $700 \mathrm{bp}$ was amplified in the infected MAGIC-5A cells (Figure 3A and $B$, lane 2 in the upper panel). In contrast to these results, no PCR products were amplified from the infected 


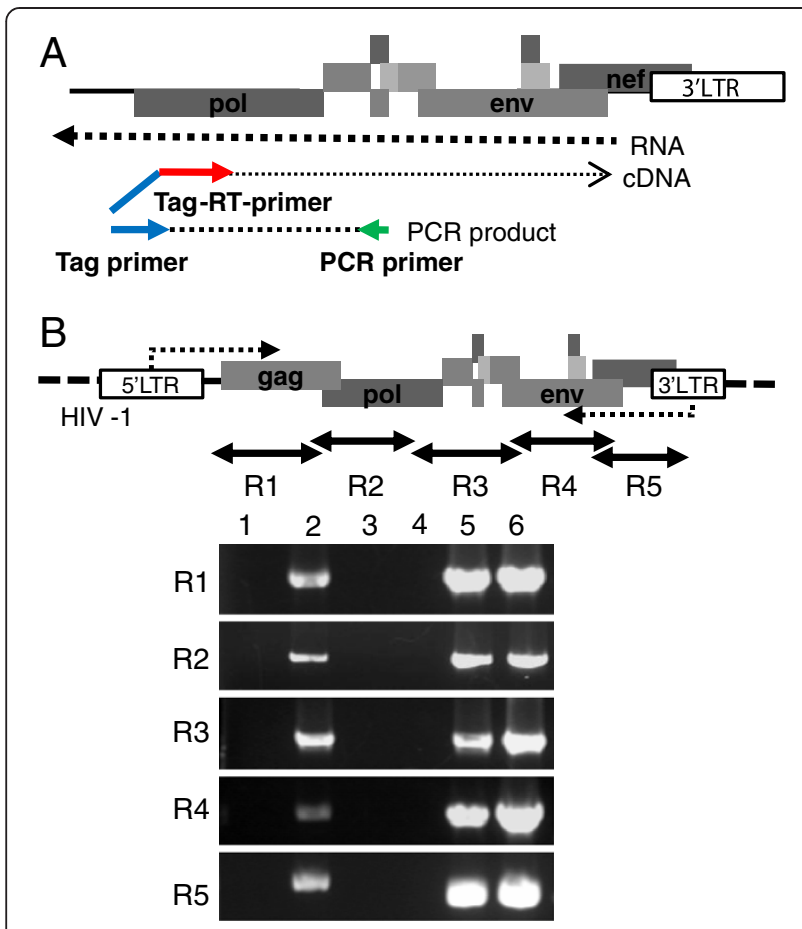

Figure 2 Antisense-specific RT-PCR of HIV-1 RNA. (A) A diagram describing the strand-specific RT-PCR method for HIV-1 asRNA. RNA samples were reverse-transcribed by an antisense-specific primer with a $5^{\prime}$ tag sequence (Tag-RT-primer). The synthesized cDNA samples were then amplified by PCR with a primer corresponding to the tag sequence (Tag primer) and a primer complementary to the target CDNA (PCR primer). (B) Detection of asRNAs in MAGIC-5A cells infected with HIV-1 NL4-3. The top panel describes the position of R1-R5 region. Lower panels show the results of agarose gel electrophoresis of products of the antisense-specific RT-PCR targeting R1-R5 regions. PCR products were detected corresponding to all 5 regions studied. Lane 1, MAGIC-5A without virus; Lane 2, MAGIC-5A with HIV-1 NL4-3; $_{\text {ine }}$, no RTase control; Lane 4, no RT primer control (a control for endogenous priming); Lane 5, PCR products with conventional primer pairs with cDNA samples synthesized by random primers (for testing sense and antisense RNA expressions); Lane 6, positive control (amplified from pNL4-3 plasmid DNA)

MAGIC-5A cells with the p3R primer (Figure 3B, lane 2 in the lower panel).

Semi-nested PCR using the PCR product by 3' RACE with $\mathrm{P} 4 \mathrm{R}$ primer produced one major product and one minor product, about 500 and 600 bp in size, in the infected MAGIC-5A cells. Analysis of the nucleotide sequences of these PCR products revealed a major poly (A) addition site that is located at the nucleotide position 6878 and other minor ones. Among the minor ones, one that extends to the nucleotide position 6783 corresponds to the larger PCR product. Thus, the results collectively showed that two groups of HIV-1 asRNAs were polyadenylated at nucleotide position 6878 (the major one) and 6783 (the minor one) in the env region (Figure 3C), which corresponds to the region of transcript III-iii (Figure 1C). In silico prediction identified a polyadenylation signal at nucleotide positions 6909 to 6918, which seems to be involved in the termination of the asRNA (Figure 3C).

Next, we studied the initiation site of the asRNA by using two reverse primers (9418r and 9538r). Antisense-specific RT-PCR with the primer 9418r successfully amplified a cDNA, whereas that with 9538r primer did not (Figure 3D). These results suggested that the transcriptional start site (TSS) is located between 9418 and 9538 of the proviral DNA. We next performed $5^{\prime}$ RACE to determine the TSS of the antisense transcript in the infected MAGIC-5A. The results indicated that the main TSS is at 9451 (Figure 3E), a finding supported by the successful amplification of cDNA by antisense-specific RT-PCR targeting the region between nucleotide positions of 6878 and 9451 (data not shown). In silico analysis predicted that this asRNA contains a few ORFs, of the previously reported ASP mRNA [8] and an extended 3' UTR of approximately 500 bases compared with that of ASP mRNA (Figure 3A). The RT-PCR results suggested that this asRNA was mainly detected in infected MAGIC-5A cells (See Additional file 3: Figure S3).

Taken together, we have identified two new forms of asRNAs that are transcribed from the nucleotide position 9451 in the 3' LTR U3 region of HIV DNA and terminated at nucleotide position 6878 or 6783 in the env region. We named these variants "ASP RNA-Long variant" $(A S P-L)$ [GenBank: JQ866626]; a major variant terminated at 6878 is named as "ASP-L1," and a minor variant terminated at 6783 as "ASP-L2."

\section{Transcriptional activity of the LTR in the antisense orientation}

Since the transcription start sites (TSSs) of the newly characterized HIV-1 asRNAs are in the U3 region of 3' LTR, the R-U5 region is expected to have antisense promoter activity. To study the promoter activity, we first performed a computational analysis of this region. The results revealed a potential TATA box at the nucleotide position -48 to -54 from the TSS as well as a couple of potential motifs that are recognized by transcription factors, such as CdxA, Nkx-2, and AP-1 (Figure 4A). To experimentally verify the promoter activity of this region, we performed luciferase reporter assays in Molt-4 cells using three kinds of constructs that have varying lengths of U3R-U5 region (300 bp to140bp) in the antisense orientation (pGL4-asLTR-1, pGL4-asLTR-2, and pGL4-asLTR-3) (Figure 4A). Transfection of pGL4-asLTR-1 demonstrated a luciferase activity, the level of which was approximately one-third of that of the sense orientation LTR (pGL4-5' LTR) (Figure 4B). Luciferase reporters having shorter regions (pGL4-asLTR-2 and pGL4-asLTR-3) also showed similar levels of promoter activities. On the other hand, a control construct that had a DNA fragment of the env 


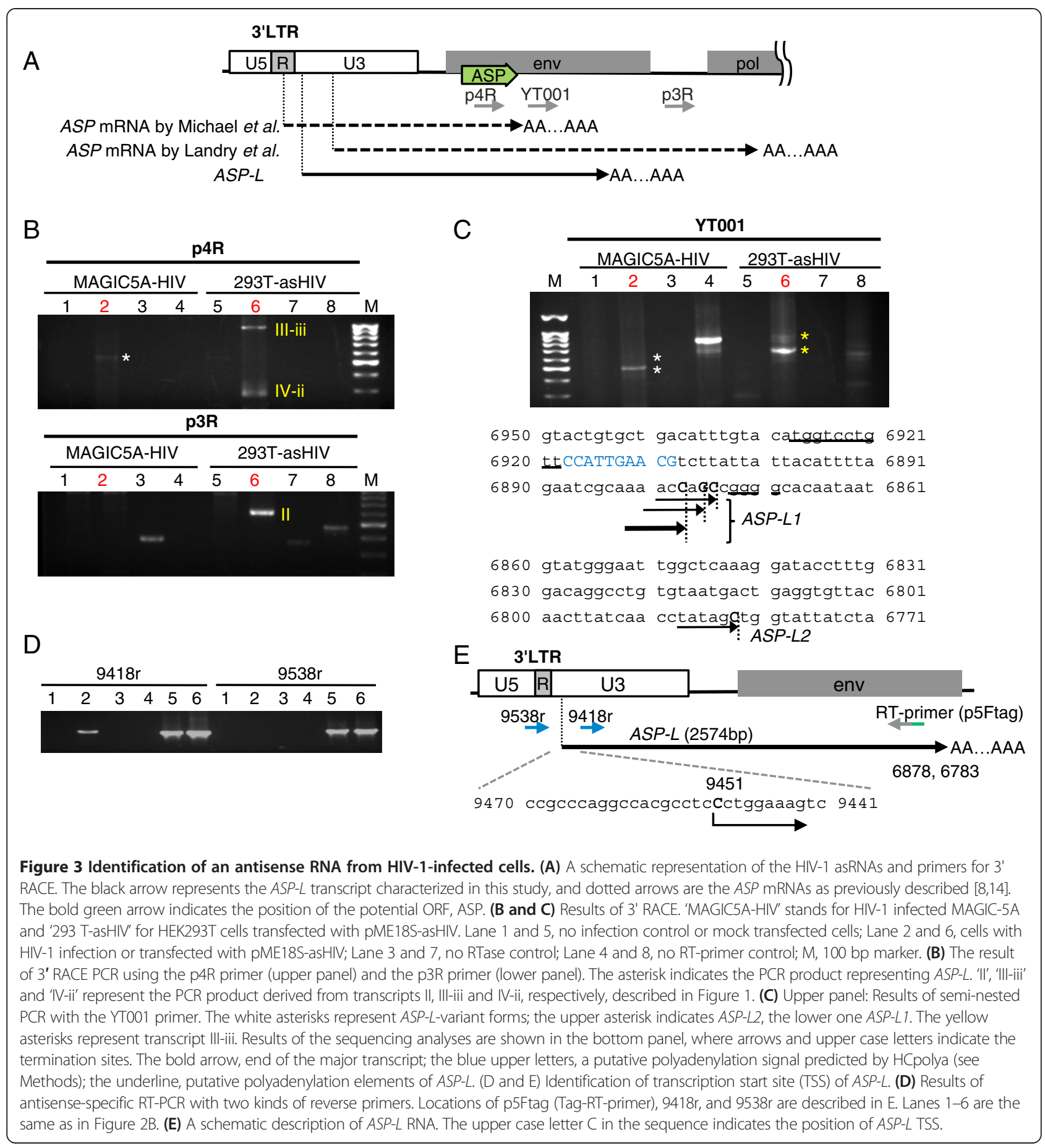

region in the reverse orientation did not show any promoter activity.

To study the regulation of promoter activity of the LTR in the antisense orientation (asLTR), we next tested whether the viral accessory protein, Tat, or a cellular cytokine, TNF- $\alpha$ modulates the activity. Results of cotransfection experiments with a Tat expression plasmid did not show any activation of the antisense promoter, whereas the sense orientation LTR (pGL4-5' LTR) responded to Tat in a dose-dependent manner, as expected (Figure 4C). On the other hand, TNF- $\alpha$ activated pGL4-asLTR-1 in a dose-dependent manner as was observed on the pGL4-5' LTR (Figure 4D). TNF- $\alpha$ treatment of $\mathrm{ACH}-2$ activated the expression of both strands (See Additional file 4: Figure S4).

The results shown in Figure 4D suggested the involvement of NF- $\mathrm{kB}$ in the regulation of 3' LTR promoter activity in the antisense orientation. To examine this possibility, we prepared a mutant reporter (pGL4-asLTR- 


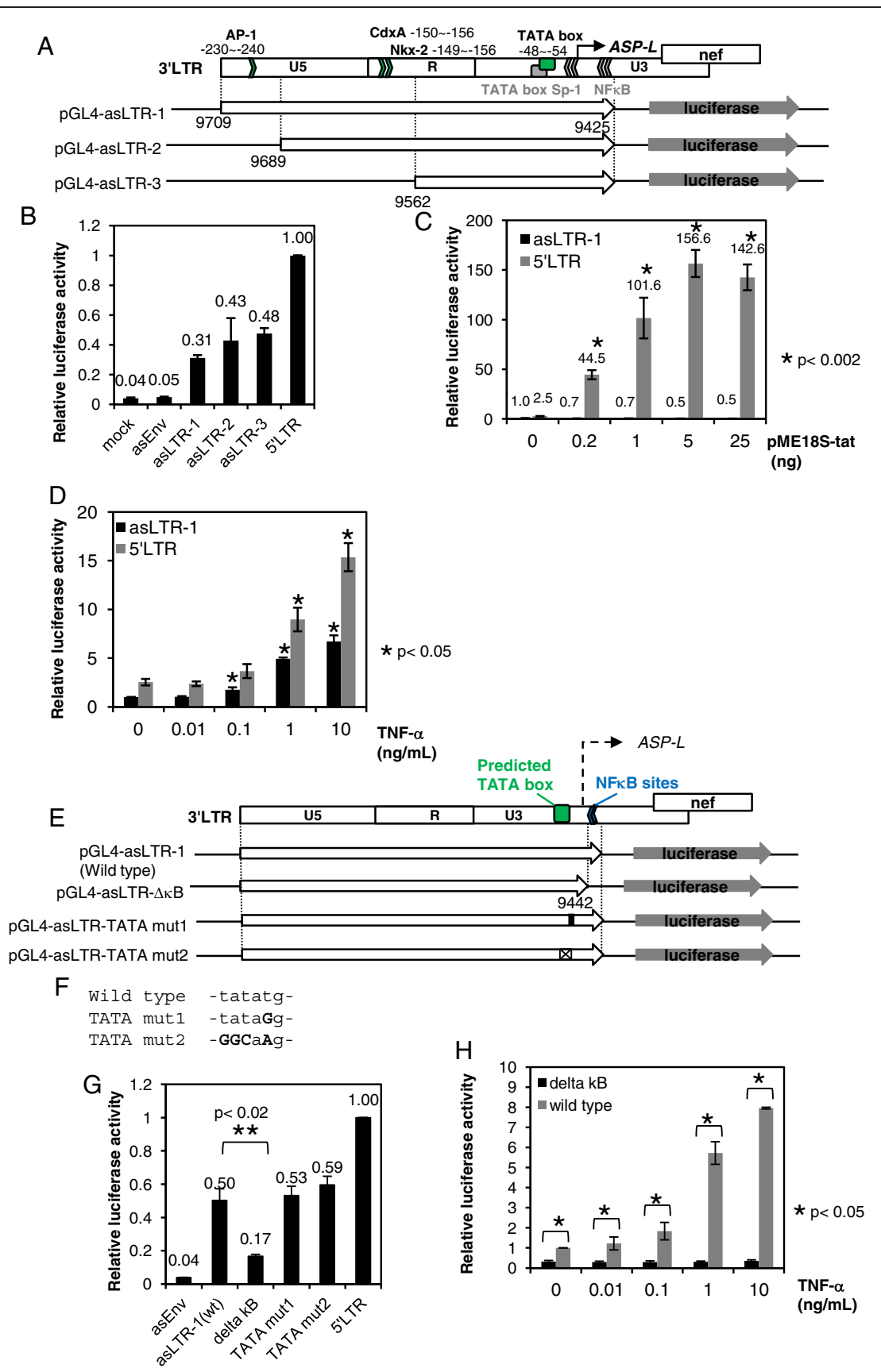

Figure 4 Transcriptional activity of the HIV-1 3' LTR in the reverse orientation. (A) A map of HIV-1 3' LTR and reporter plasmids. Top panel shows results of promoter prediction of the $5^{\prime}$-flanking region of the ASP-L TSS by TFsearch and Genetyx. Green box indicates putative TATA box. The sequence of the putative TATA box is described in F. The bottom panels are the structures of pGL4-asLTR-1, pGL4-asLTR-2 and pGL4-asLTR-3 plasmid. (B) Promoter activities of the LTR in the antisense orientation (asLTR). pGL4-5' LTR and pGL4-asEnv plasmids were used as positive and negative controls, respectively. mock, pGL-4.10; asEnv, pGL4-asEnv; asLTRs, pGL4-asLTR-1, pGL4-asLTR-2 and pGL4-asLTR-3; 5' LTR, pGL4-5' LTR. The luciferase activities relative to that of pGL4-5' LTR are shown. (C) Effects of Tat protein on the asLTR promoter activity. A Tat expression plasmid, pME18S-tat, was cotransfected with pGL4-asLTR-1 or pGL4-5' LTR. (D) Dose-response effects of TNF-a on the asLTR promoter activity. At $12 \mathrm{~h}$ post-transfection of the reporters, cells were treated with various amounts of TNF-a $(0-10 \mathrm{ng} / \mathrm{mL})$ for $12 \mathrm{~h}$. (E-H) Investigation of transcriptional regulatory elements in the asLTR. (E) A schematic description of series of asLTR mutant reporters. asLTR- $\Delta K B$ lacks two NF-KB binding sites. asLTR-TATA mut1 and mut2 contain mutated TATA box. (F) Sequences of the potential TATA box mutants. (G) Promoter activities of the asLTR mutants. The luciferase activities relative to that of pGL4-5' LTR are shown. (H) Effects of TNF-a on the $\triangle K B$ mutant. The experimental condition is identical to D. 'delta kB' stands for pGL4-sLTR- $\triangle K B$. 'wild type' stands for pGL4-asLTR-1. The mean \pm S.D. of quadruplicate (B) or triplicate $(C, D, G$, and H) experiments are shown. The asterisks shown in $C, D, G$, and $\mathrm{H}$ indicate statistical significance. 
$\Delta \kappa B$, Figure $4 E$ ), which has a deletion of NF $-\kappa B$ binding motifs. The basal promoter activity of the asLTR $-\Delta \kappa B$ was significantly decreased compared with that of wild type (Figure 4G) and lost responsiveness to TNF- $\alpha$ treatments (Figure $4 \mathrm{H}$ ). We further tested the possible involvement of the putative TATA box using two kinds of mutant reporters, pGL4-asLTR-TATA mut1 and pGL4-asLTRTATA mut2 (Figure 4E and F). pGL-4asLTR-TATA mut1 has a $T$ to $G$ point mutation at the potential TATA box, which lacks a TATA activity [45,46]. pGL-asLTR-TATA mut2 has mutations with a deletion of the TATA motif. The results demonstrated no difference in the basal promoter activity compared with that of wild type asLTR (Figure 4G).

\section{$A S P-L$ expression in various types of cells infected with HIV-1}

To study the expression of HIV-1 asRNAs in various types of HIV-1-infected cells, we analyzed RNA samples from Molt-4 acutely infected with $\mathrm{HIV}-1_{\mathrm{NL} 4-3}$, as well as in $\mathrm{ACH}-2$, and OM10.1 cell lines that are chronically infected with HIV-1 $1_{\text {IIIB }}[47,48]$ with the antisense-specific RT-PCR. In this experiment, we designed an antisense-specific RTPCR with a Tag-RT-primer that does not amplify the ASP mRNA reported by Michael et al. [8] (Figure 5A). The asRNA expression was detected in all the cell lines examined (Figure 5B). Furthermore, we could also detect asRNA in the PHA-activated PBMCs infected with HIV$1_{\mathrm{NL} 4-3}$ (Figure $5 \mathrm{C}$ ). 3' RACE analyses revealed similar transcription termination in OM10.1 and activated $\mathrm{ACH}$ 2 cells, where HIV-1 $1_{\text {IIB }}$ also had a conserved polyadenylation signal (Figure 5D). By antisense-specific RT-PCR analyses, we demonstrated that TSS of $A S P-L$ from HIV-1 $1_{\text {IIB }}$ was located between nucleotide positions 9441 and 9538 that correspond with that from $\mathrm{HIV}_{\mathrm{NL4}-3}$ (Figure 5E). Collectively, $A S P-L$ was demonstrated to be transcribed in cell lines with acute or chronic infection as well as in primary human PBMCs infected with HIV-1.

To evaluate the expression levels of the asRNA in various cells, quantitative analysis was performed using the strandspecific quantitative RT-PCR method (qRT-PCR) of the R7 region (Figure 5A and 5F). The results showed that the highest expression level was observed in OM10.1. The expression levels of HIV-1 asRNAs were shown to be 1002,500 times less abundant than those in the sense RNA transcripts in all cells.

\section{Sub-cellular localization of HIV-1 antisense RNAs}

The subcellular localization of asRNAs could be a key to understand the possible functions of asRNAs [30,38,49]. We, therefore, studied the localization ratios of HIV-1 asRNAs between the cytoplasm and nucleus. For this purpose, HIV-1-infected MAGIC-5A and OM10.1 cells were fractionated into the cytoplasmic and nuclear portions, followed by RNA extraction. The results of antisense strand-specific RT-PCR at R8 region revealed that the majority of HIV-1 asRNAs was enriched in the nuclear fractions in both cell lines, whereas the sense strand transcripts did not show such a biased distribution (Figure 6A). To evaluate the distribution more quantitatively, we next employed qRT-PCR at the $\mathrm{R} 7$ region. The results revealed that more than $77 \%$ of the asRNA is located in the nuclei of various cells including primary PHA-activated PBMC (Figure 6B-D). This significantly biased nuclear localization was also confirmed in ACH-2 and HIV-1-infected Molt-4 (See Additional file 5: Figure S5. Sub-cellular localization of HIV-1 antisense RNAs in the HIV-1 infected T cell lines). Taken together, these results indicate that ASP RNAs are localized mainly in the nuclei of the acutely or chronically infected cell lines as well as in the nuclei of primary PBMCs newly infected by HIV-1.

\section{Inhibitory effects of the antisense RNA on HIV-1 replication}

To understand the function of HIV-1 asRNAs, we studied the effects of $A S P-L$ on HIV-1 replication. MAGIC-5A cells were transiently transfected with an $A S P-L$ expression vector, pIRES-RSV-ASP-L, or a vacant vector, followed by infection with HIV-1. At $48 \mathrm{~h}$ post-transfection (p.t.), the levels of gag RNA decreased in ASP-L-expressing cells compared to those in the control cells (Figure 7A). Semiquantitative PCR analysis of the genomic DNA did not show any significant differences in the copy numbers of the proviral DNA at p.t. 24 h, whereas it showed decreased levels of proviral DNA in ASP-L-expressing cells at p.t. 48 and $72 \mathrm{~h}$ (Figure $7 \mathrm{~B}$ ). When the virus production was evaluated by RT assays with the culture supernatants, it was decreased in the $A S P$ - $L$-expressing cells at p.t. $72 \mathrm{~h}$ with statistical significance $(p<0.002)$ (Figure $7 C)$.

To study the inhibitory effects of $A S P-L$ on HIV-1 replication in T-cells, we prepared three clones of Molt-4 that stably express $A S P-L$ (3C2, 3F1, and 3G9). After infecting these cells with HIV-1, viral replication was evaluated by RT assays. The results demonstrated a significant repression of viral replication in the $A S P$ - $L$-expressing cell lines for more than 30 days post HIV-1 infection (dpi) (Figure 7D). qRTPCR analysis of the HIV-1 sense strand RNA did not show any significant differences in the levels of gag and tat RNAs at $1 \mathrm{dpi}$ between the ASP-L-expressing cells and mock control cells; however, it demonstrated a 5 -fold reductions in the levels of gag and tat RNAs at 4 dpi in the ASP-L-expressing cells compared to those levels in the control cells (Figure $7 \mathrm{E}$ and 7F). Semi-quantitative PCR of the genomic DNA did not show a significant difference in the proviral DNA levels between ASP-L-expressing and control cells at 1 dpi, whereas decreased levels of proviral DNA copies were shown in $A S P$ - $L$-expressing cells at 4 dpi (Figure $7 \mathrm{G}$ ). Among the stable $A S P$ - $L$-expressing cell lines, the most 


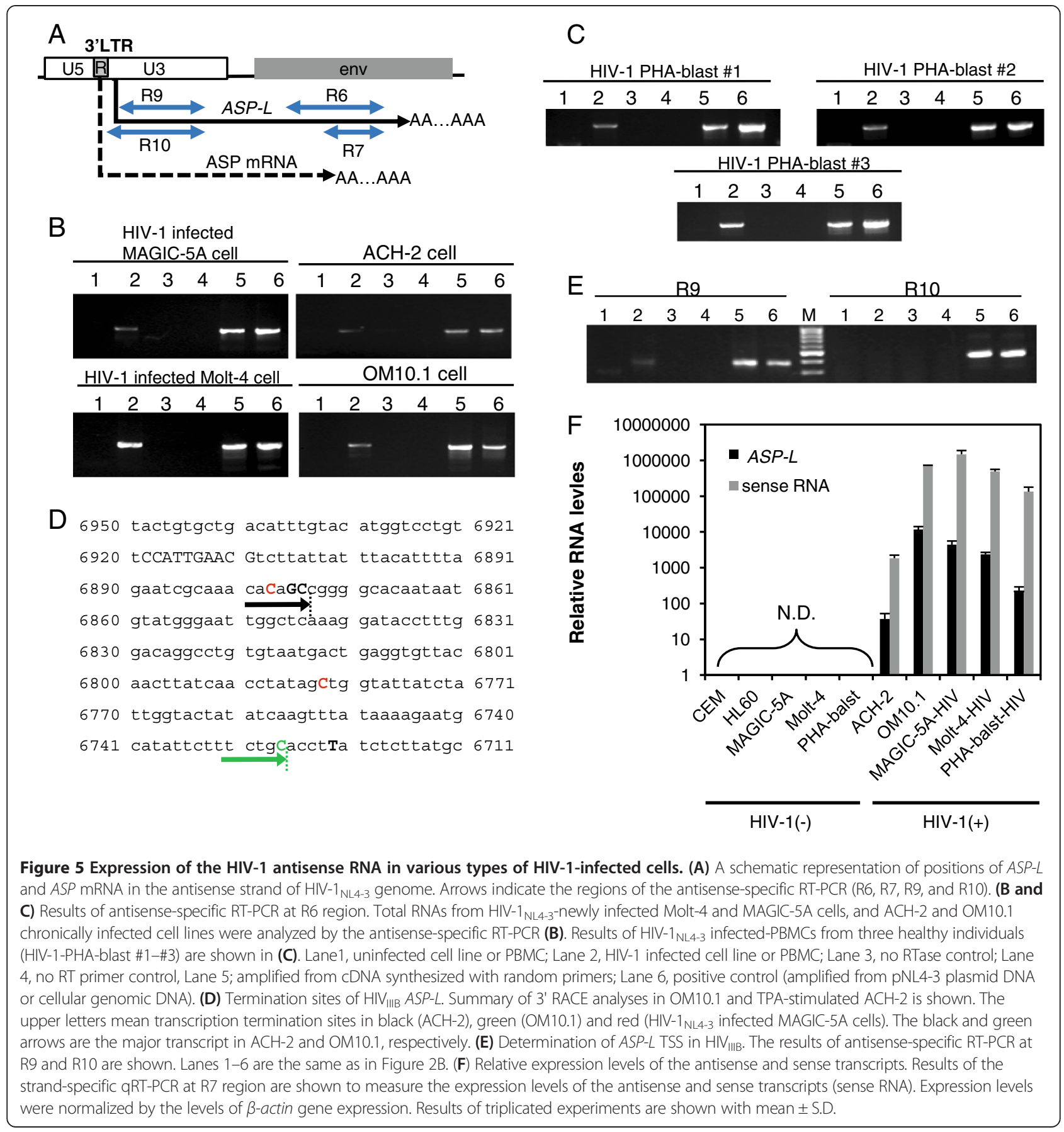

significant inhibitory effect against HIV-1 replication was observed in clone $3 \mathrm{C} 2$ that expresses the highest levels of $A S P-L$, where the level of $A S P-L$ was estimated to be about 120 times more abundant than that in OM10.1 (Figure $7 \mathrm{~F}$ and $\mathrm{H})$. Furthermore, the nuclear localization of $A S P-L$ in the $A S P-L$-expressing clones was confirmed as described above (See Additional file 6: Figure S6. Sub-cellular localization of $A S P-L$ in Molt-4 stably expressing $A S P-L)$. Contrary to above results, the cells expressing the
3' region of $A S P-L$ showed no inhibitory effect on HIV-1 replication (See Additional file 7: Figure S7A-C).

\section{Upregulation of HIV-1 expression by knockdown of the endogenous antisense RNA}

As described above, the enforced expression of $A S P-L$ downregulated the viral gene expression and replication. We then examined the biologic effects of $A S P-L$ in HIV-1 infected cells. We established Molt-4 transformants that 

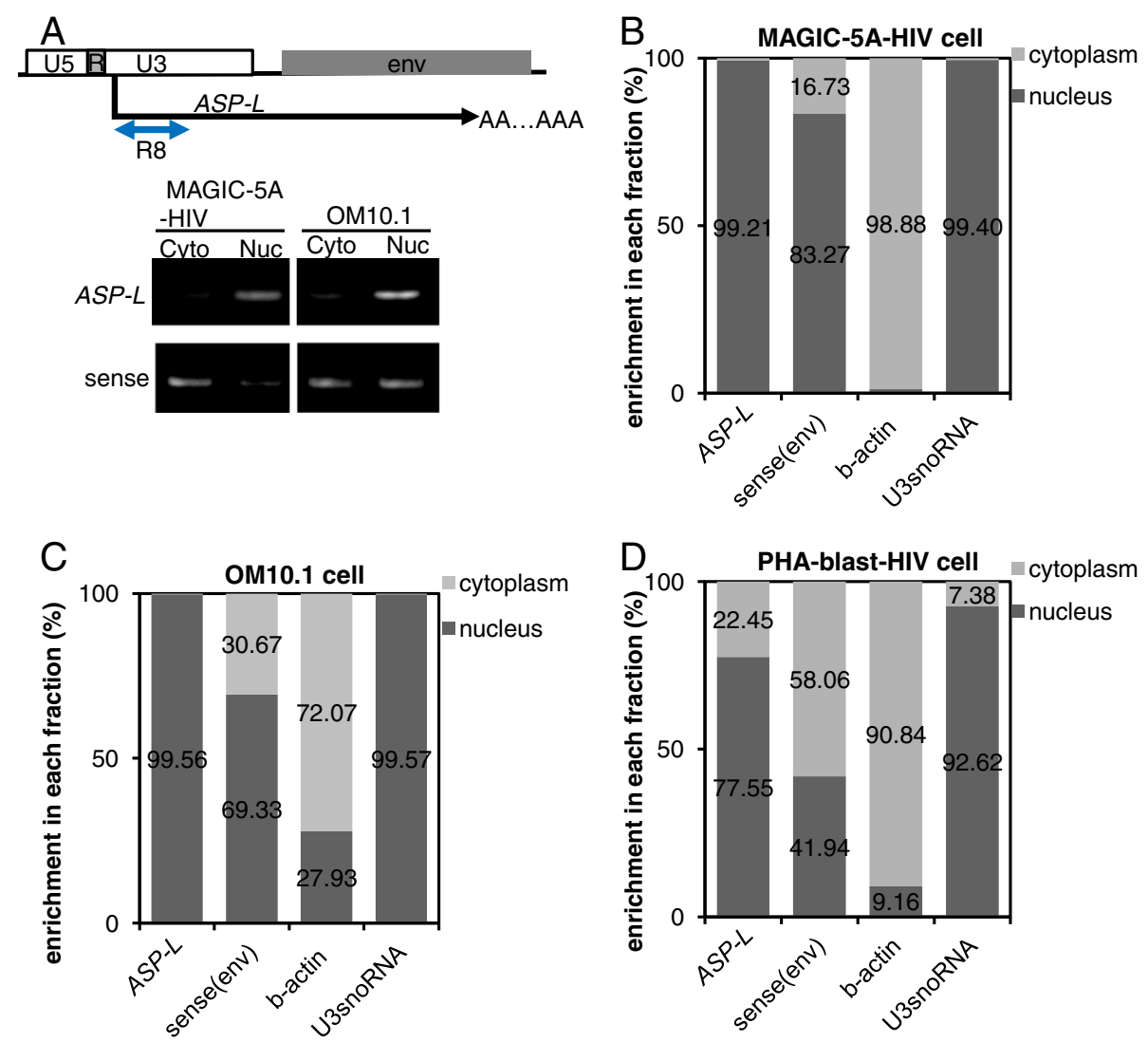

Figure 6 Sub-cellular localization of HIV-1 antisense RNAs. (A) Strand-specific RT-PCR of fractionated samples. An arrow in the upper panel indicates the region of PCR amplification (R8). Bottom panel, agarose gel electrophoresis of PCR products using samples of HIV-1-infected MAGIC-5A and chronically infected OM10.1 cells. Cyto, cytoplasmic RNA; Nuc, nuclear RNA; sense, results of sense strand-specific RT-PCR at R8. (B-D) Sub-cellular distribution of the asRNAs in various HIV-1-infected cells. Relative levels are presented in percentages for MAGIC-5A, OM10.1, and PHA-blast, as well as simultaneously measured controls. Results of $\beta$-actin cytoplasmic RNA and nuclear U3 snoRNA served as controls for fractionation efficiencies.

stably express short-hairpin RNAs (shRNAs) targeted to the HIV-1 asRNAs (shRNA\#1 and shRNA\#2, Figure 8A). To exclude the possible interference against sense strand RNAs, several mutated nucleotides were introduced into the passenger strands, which target to HIV-1 sense RNAs. First, we tested the specificity of these shRNAs using luciferase reporters having a sense or antisense sequence in these transformants. The two shRNAs specifically reduced the levels of luciferase activities of the reporters having $A S P-L$ sequence, whereas the effects were not significant for the reporters having sense strand RNA (Figure 8B). Next, we examined the effects of these shRNAs in HIV-1 replication. The expression levels of the HIV-1 asRNAs in infected cells were suppressed in these cells compared with control cells that express a scrambled sequence (Figure 8C). qRT-PCR of RNA samples from the infected cells demonstrated significant enhancements of the levels of sense HIV1 RNAs in the ASP-L-knockdown cells compared with that in the control cells (Figure 8D). Virus particle productions were evaluated by RT-assays using the supernatants of the infected cells. The RT activities were significantly enhanced in the samples of stable transformants expressing shRNA\#1 and shRNA\#2 compared with that of the control cells (Figure 8E).

\section{Discussion}

In the present study, to clarify the natural structure of HIV-1 asRNAs, we employed a strategy that combines an artificial overexpression of antisense strand of HIV-1 and characterization of antisense transcripts in infected cells. The results revealed a natural form of asRNAs of HIV- $1_{\mathrm{NL} 4-3}$ and HIV-1 ${ }_{\mathrm{IIIB}}, A S P-L$.

$A S P-L$ appears to be a variant of previously reported $A S P$ mRNA [8], in that it shares most of the region of the ASP mRNA, but lacks about 120 to 157 bases in the $5^{\prime}$ region and extends to the $3^{\prime}$ end by about 499 to 574 bases (Figure 3A). Previously, two groups reported structural analyses of ASP mRNAs (Figure 3A); first, Michael et al. isolated a single $\mathrm{cDNA}$ for $A S P$ mRNA from a cDNA library prepared from A3.01 cells infected with HIV-1 $1_{\text {IIIB }}$ [8]. The transcript started at the nucleotide position 9608 and polyadenylated at the nucleotide position 7367 of the HXB2 

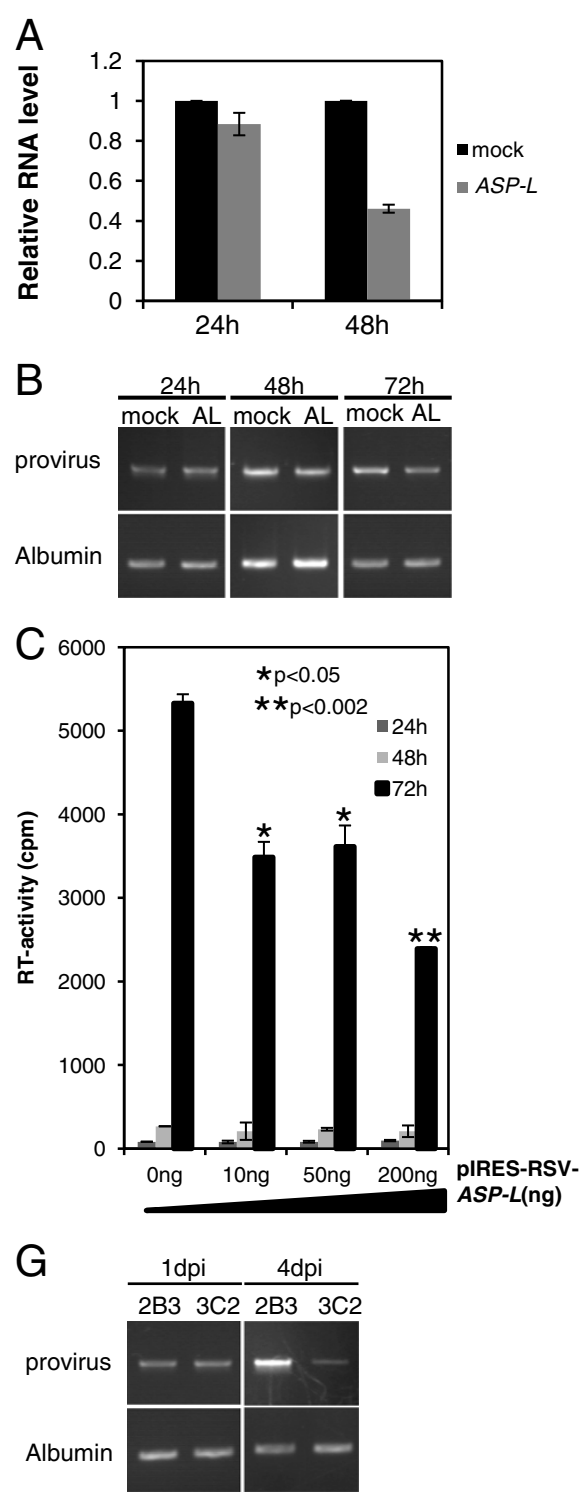

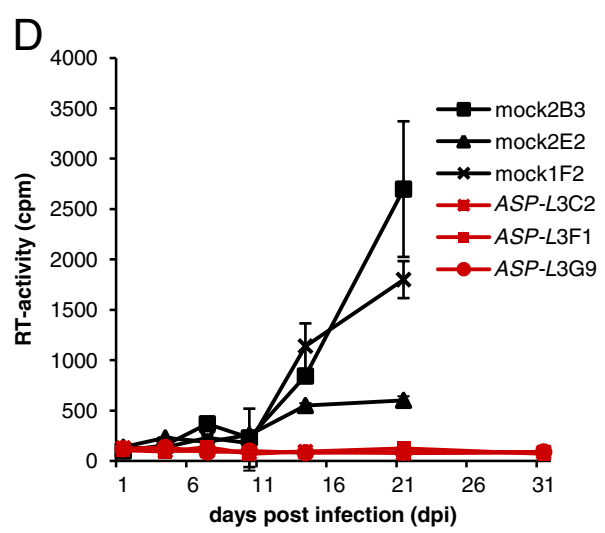

$E$
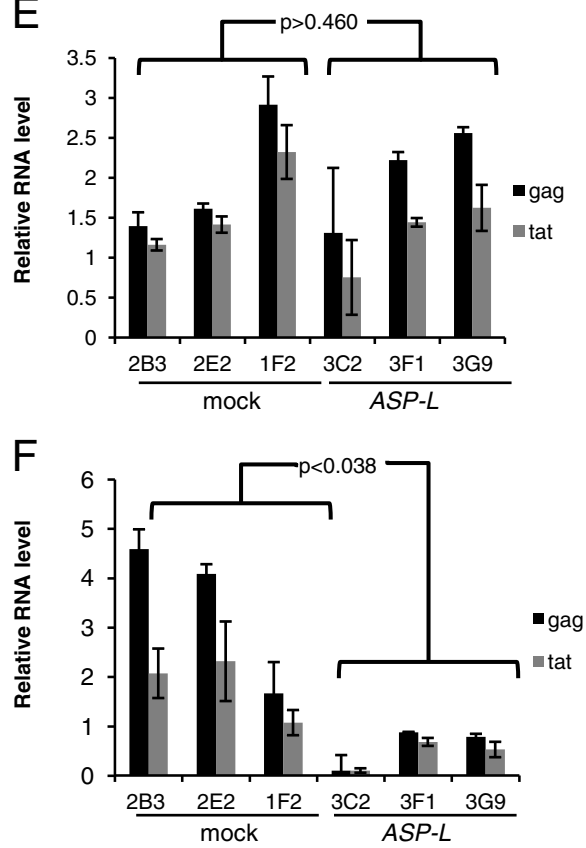

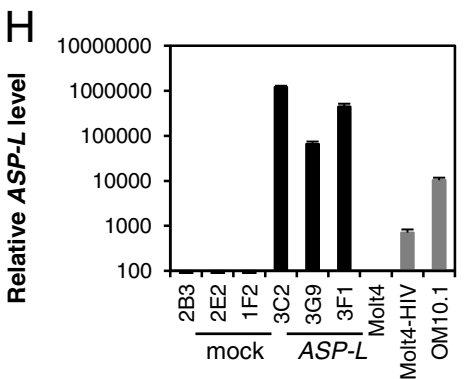

Figure 7 ASP-L-mediated inhibition of HIV-1 replication. Results of transient transfection experiments are shown in A to C. (A) HIV-1 RNA levels at the indicated time points with prior transfection of the ASP-L expression vector, pIRES-RSV-ASP-L, or a vacant vector into MAGIC-5A cells. The relative expression levels of HIV-1 gag RNA are presented relative to that of HIV-1 gag RNA expressed in mock-transfected cells set as 1.0. (B) Agarose gel electrophoresis of PCR products of semi-quantitative PCR of genomic DNA samples harvested at the indicated time points. 'AL' stands for pIRES-RSV-ASP-L transfected cells. (C) The levels of viral particle production in culture supernatants evaluated by RT assays. MAGIC-5A cells were transfected with the indicated amounts of the ASP-L expression vector before infection with HIV-1. (D-H) Prolonged inhibition of HIV-1 replication in ASP-L expressing Molt-4 clones. Three clones that stably express ASP-L and three clones transfected with the vacant vector were used. (D) The levels of virus production evaluated by RT assays. (E and F) HIV-1 RNA levels at 1 day (E) and 4 days (F) post infection (dpi) measured by qRT-PCR. (G) Agarose gel electrophoresis of PCR products of semi-quantitative PCR of genomic DNA samples at 1 and 4 dpi.. (H) The relative expression levels of $A S P-L$ that were measured by qRT-PCR. 


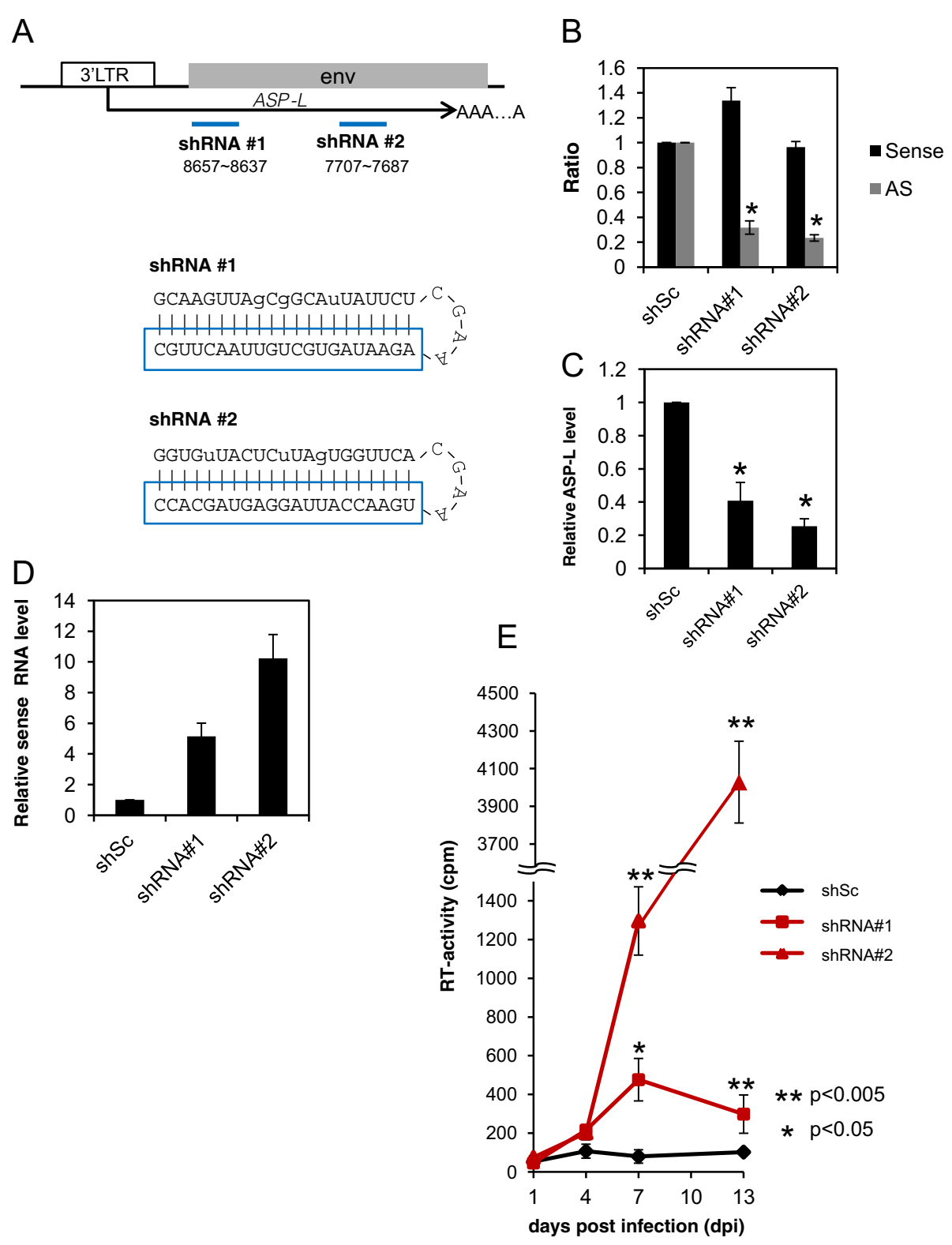

Figure 8 Effects of endogenous HIV-1 antisense RNA on HIV-1 expression. (A) Targeted regions of shRNA\#1 and \#2. Lower panel depicts secondary structures of expressed shRNAs predicted by $\mathrm{m}$-fold. Lower case letters indicate mutated sites. Boxed sequences are guide strand for HIV-1 asRNAs. (B) Reporter-based confirmation of strand-specific knockdown. Luciferase reporter plasmids that contain sense HIV-1 sequence or antisense HIV-1 sequence were transfected into the shRNA-expressing Molt-4 cells. Relative changes of luciferase activities were calculated by pMIR-sense or AS ASP-L/pMIR-report. The mean \pm S.D. of triplicate experiments are shown. Asterisks indicate statistical significance $(p<0.01)$. (C) Levels of endogenous HIV-1 asRNAs in HIV-1-infected shRNA expressing cells at $24 \mathrm{~h}$ of infection evaluated by strand-specific qRT-PCR at R7. Asterisks indicate statistical significance $(p<0.009)$. (D) HIV-1 sense RNA levels at 4 dpi measured by strand-specific qRT-PCR at R7 (env region). (E) Levels of viral particle production. At the indicated time points, cultured supernatant were collected and subjected to RT-assay. Asterisks indicate statistical significance.

strain, just after the TGA codon. Although a similar transcript was identified in our overexpression experiments (transcript IV-ii), this transcript was not identified in our experiments using HIV-1 infected cells (Figure 3B).

Secondly, Landry et al. reported the structure of another "ASP mRNA" in $293 \mathrm{~T}$ cells transfected with a 5' LTR- deleted pNL4-3 [11]. The transcript started at various positions in the $5^{\prime}$ region of the $3^{\prime}$ LTR, and terminated in the pol region where they found a poly (A) signal at the nucleotide position 4908. This transcript appears to correspond to the transcript II in our overexpression experiments (Figure 1C); however, this transcript was detected only in 
the 293 T cells transfected by the antisense HIV-1 expression vector, but not detected in the HIV-1 infected cells in our experiments (Figure 3B), suggesting that this form of transcripts may be an artifact in overexpression experiments. As for transcript I, the asRNAs could not be detected by 3' RACE method; nevertheless, its expression was suggested by the antisense-specific RT-PCR in the infected MAGIC-5A (Figure 2B). These results suggested that the expression level of transcript I is lower than that of ASP-L.

The results of reporter assays and 5' RACE strongly support the notion that asRNAs of HIV-1 are transcribed from 3' LTR sequence (Figures 3 and 4). Furthermore, consistent with previous reports $[8,15,50]$, our reporter gene assays suggested that the asRNAs of HIV-1 could be transcribed from 3' LTR in a TATA - independent and NF-kB - dependent manner (Figure 4D-H). On the other hand, the absence of TAR sequences in the antisense transcript may explain the absence of response to Tat (Figure $4 \mathrm{C}$ ). These results also imply a possibility that the $5^{\prime}$ LTR may possess a promoter activity in the antisense direction, which might contribute to modulate the expression of flanking cellular genes [6]. In addition to our findings, there remains a possibility that the antisense promoter activity may also be influenced by flanking host sequences and the action of cellular transcription factors, since HIV-1 prefers to integrate into intergenic regions of actively transcribed genes [6,51]. Also, the transcription of asRNAs might be initiated within the host flanking sequences in some cases [20].

The results of antisense-specific qRT-PCR analyses indicated that the ratio of expression levels of HIV-1 asRNAs to those of the sense transcripts varied among the cells examined ( $1 / 100$ to $1 / 2500$, Figure $5 F)$. Our result was similar to that of a previous study in which the authors estimated $0.9 \%$ abundance of HIV-1 asRNAs to the sense transcriptions [18]. The ratio of expressions was maintained at various stages of $\mathrm{HIV}-1$ infection in Molt-4 (data not shown), implying a biological meaning of $A S P-L$ in a life cycle of HIV-1. Taking our data described in Figures 7 and 8 into consideration, HIV-1 might retain a balanced expression of sense and antisense genes to avoid acute toxicity. In addition, the relative expression levels of HIV-1 asRNAs compared with those of $\beta$-actin were confirmed to be comparable to those of mRNAs of well-known protein encoding genes with important functions such as $\mathrm{Bcl}-2$, Cyclin $D 1$ and $I L-2$ (data not shown).

To address the biological roles of the asRNA, we performed two experimental studies; first, using cells that stably overexpress $A S P-L$, we showed that $A S P-L$ inhibits HIV-1 gene expression for a prolonged period (Figure 7). Since $A S P-L$ expression did not affect the levels of HIV-1 DNA and RNA at $24 \mathrm{~h}$ post-transfection (Figure 7A, B, E, and $\mathrm{G}), A S P-L$ does not appear to inhibit the early processes of infection, such as viral entry and integration into the genomic DNA of target cells.
Next, we performed knockdown assays against the HIV asRNAs (Figure 8). The results suggested that asRNAs of HIV-1 including ASP- $L$ might be involved in suppressing sense strand viral expression. Differences in the efficiency of viral replication between shRNA\#1 and \#2 may partly be attributed to their knockdown abilities (Figure $8 \mathrm{~B}$ and $\mathrm{C}$ ), although precise mechanisms need to be further studied. Taken collectively, the results suggest that the asRNAs may be a natural repressor for HIV-1 gene expression, which may contribute to a self-limited replication.

We demonstrated nuclear localization of $A S P-L$ in the present study (Figure 6, Additional file 5: Figure S5 and Additional file 6: Figure S6). Furthermore, our data shown in Additional file 7: Figure S7 and Additional file 8 suggest that ASP protein may not be required for the antiviral function on HIV-1. These observations suggest a function of $A S P-L$ that is exerted as a functional RNA. One previous study also raised a possibility that $A S P$ mRNA may act as a functional RNA [13]. Recent reports demonstrated that the nuclear mRNA-like noncoding RNAs such as Xist and HOTAIR have important roles in regulating the sense strand gene expressions [39,52]. In addition, there is a possibility that $A S P-L$ could be processed into small interference RNAs reducing HIV-1 replication [20].

However, considering a previous report that suggested the presence of antibodies that recognizes ASP protein in the sera of HIV-1 carriers [9], there remains a possibility that HIV asRNA may exert its functions both as a functional RNA and through protein(s) encoded by it. Considering the function of asRNA of human retroviruses, one intriguing example would be HBZ of HTLV-1. It has been reported that bZIP protein encoded by $H B Z$ RNA can suppress transcription of HTLV-1 sense RNA [22,26], although antibodies that recognize HBZ have not been reported in sera of HTLV-1-infected individuals. In addition, some reports have suggested that $H B Z$ RNA itself can regulate host cellular proliferation [24,25]. Further studies are required to elucidate detailed functional mechanisms of $A S P-L$ and its putative translation product (s).

\section{Conclusions}

We have identified a $2.6 \mathrm{~kb}$ asRNA of HIV-1, a variant of ASP mRNAs, which is transcribed from the $\mathrm{U} 3$ region of antisense strand of $3^{\prime}$ LTR and terminates in the env region. The asRNA was expressed in acutely or chronically infected cells and localized in the nuclei. The expression of the asRNA led to a prolonged inhibition of HIV-1 replication, and the knockdown of the ASP-L RNA significantly enhanced viral replication, suggesting that HIV-1 asRNA may be a novel factor for the self-limiting replication of HIV-1. Our finding of a new regulatory asRNA of HIV-1 will improve our understanding of regulatory mechanisms 
of viral replication, potentially providing a new approaches for anti-viral therapies.

\section{Availability of supporting data}

The data sets supporting the results of this article are included within the article and its additional files.

\section{Methods}

\section{Cells and viruses}

HEK293T and MAGIC-5A cells [44] were maintained in DMEM (Dulbecco's modified Eagle's medium, Nissui) supplemented with $10 \%$ of heat-inactivated fetal bovine serum (FBS, GIBCO) and antibiotics. The following cell lines were maintained with RPMI 1640 medium with $10 \%$ FBS and antibiotics: Molt-4, CEM, HL60, ACH-2 (CEM cell-derived HIV-1 $1_{\text {IIIB }}$ chronically infected cell line) [47] and OM10.1 (HL-60 cell-derived HIV-1 IIIB $_{\text {chronically infected }}$ cell line) [48]. Human PBMCs were isolated from whole blood of healthy donors by Ficoll-Paque gradient centrifugation (Amersham Biosciences) and stimulated with $10 \mathrm{ng} /$ $\mathrm{mL}$ of PHA-P (Sigma) for $48 \mathrm{~h}$. The activated PBMCs (PHA-blasts) were cultured in RPMI 1640 medium supplemented with $10 \%$ FBS, antibiotics and $20 \mathrm{U} / \mathrm{mL}$ of human recombinant IL-2 (R\&D systems). HIV-1 NL4-3 strain was used for the infection studies. Viral particles were produced by calcium phosphate transfection of pNL4-3 plasmid in HEK293T cells as previously described [53].

\section{Expression vectors}

Primers used for generating expression vectors are described in Additional file 9: Table S1. Primers used for this study. pME18S-asHIV was used for expression of the antisense strand of HIV-1 $1_{\text {NL4-3 }}$ (nucleotide position is 653 to 9102). The antisense strand of HIV-1 was obtained by PCR method with following primers: hiv-pnl-653 and hivpnl-9102, which are prepared based on the nucleotide sequence of pNL4-3 [53]. The PCR product was cloned into pGEM-Teasy (Promega) by TA method and subcloned into XbaI/NotI sites of pME18S [54].

The reporter gene plasmids, pGL4-asLTR-1, pGL4asLTR-2, pGL4-asLTR-3 and pGL4-asLTR- $\Delta \kappa B$ were generated by inserting PCR amplified fragments with varying length of the upstream sequence of ASP-L TSS into SacI (blunted)/XhoI sites of pGL4.10 (Promega). The fragments correspond to the following nucleotide positions of HIV-1 ${ }_{\text {NL4-3 }}$ : pGL4-asLTR-1, nucleotide position 9425 to 9709; pGL4-asLTR-2, 9425 to 9689; pGL4-asLTR-3, 9425 to 9562; pGL4-asLTR- $\Delta$ kB, 9442 to 9709. pGL4-asEnv was generated by insertion of 200 bp length antisense fragment of env region that was amplified by $\mathrm{p} 5 \mathrm{R}$ and 8514f primers, followed by XbaI/XhoI digestion. pGL4-5' LTR vector for evaluating the transcriptional activity of the sense strand LTR was described previously [55]. The TATA box mutants, pGL4-asLTR-TATA mut1 and pGL4-
asLTR-TATA mut2, were prepared by site-directed gene mutagenesis method [56,57] with primers described in additional file 9. These vectors were linearized by digestion with PstI or BstXI prior to transfection. pME18S-tat was used for Tat expression $[58,59]$.

To investigate the effect of $A S P$ - $L$ on HIV-1 replication, we prepared an $A S P-L$ expression vector, pIRES-RSV- $A S P$ $L$, using an expression vector pIRES-RSV that was derived from pIRESpuro3 (Clontech) containing RSV promoter. pIRES-RSV- $A S P-L$ was generated by inserting a proviral DNA fragment that corresponds to the full-length of $A S P-L$ at EcoRI/NotI sites. The ASP- $L$ fragment was obtained by PCR from pNL4-3 with primers 6878f-NotI and 9460r.

\section{Transfections and HIV-1 infections}

HEK293T cells $\left(5 \times 10^{6}\right)$ were transfected with $4 \mu \mathrm{g}$ of plasmid DNA, pME18S-asHIV or pME18S, as a control, by Lipofectamine reagent (Invitrogen) according to the protocol of the manufacturers. After $4 \mathrm{~h}$ incubation, the culture medium was changed and incubated additionally for $44 \mathrm{~h}$. To obtain the RNA from HIV-1-infected cells, $1.5 \times 10^{6}$ of MAGIC-5A cells were inoculated with HIV $_{\text {NL4-3 }}\left(3 \times 10^{3} \mathrm{TCID}_{50} / 50 \mathrm{ml}\right)$ for 3 days. Total RNA was isolated by ISOGEN reagent (WAKO, Japan), followed by poly $(\mathrm{A})^{+}$RNA selection by oligo (dT) latex (Dai-ichi Kagaku Yakuhin, Japan).

For expression of $A S P-L$ gene, $200 \mathrm{ng}$ of pIRES-RSV or pIRES-RSV- $A S P-L$ were transfected by Lipofectamine 2000 reagent (Invitrogen). After $4 \mathrm{~h}$ incubation, culture medium was changed, followed by inoculation of $\mathrm{HIV}_{\mathrm{NL} 4-3}$ at 200 $\mathrm{TCID}_{50} / 50 \mathrm{ml}$. After incubation for $18 \mathrm{~h}$ with HIV-1, cells were washed with DMEM to remove free viruses.

For establishment of $\mathrm{T}$ cell lines that stably express $A S P-L, 5 \times 10^{6}$ of Molt- 4 cells were transfected with pIRES-RSV- $A S P-L$ by electroporation, and several clones were selected by $0.5 \mu \mathrm{g} / \mathrm{mL}$ of Puromycin (Sigma). Among the Puromycin-resistant clones, three clones were selected based on the $A S P-L$ expression confirmed by RT-PCR (3C2, 3F1, and 3G9). These clones were expanded and inoculated with $\mathrm{HIV}_{\mathrm{NL4}-3}$ at $\mathrm{MOI}=0.1$. After $24 \mathrm{~h}$ of viral attachment, cells were washed by PBS and cultured in a 6-well plate.

\section{Northern blot analysis}

Ten micrograms of total RNA samples were separated by $1 \%$ agarose-formaldehyde gel electrophoresis, and transferred onto a Biodin-A membrane (Pall). Hybridization was carried out with $7 \%$ SDS, $0.2 \mathrm{M} \mathrm{Na}_{2} \mathrm{HPO}_{4}$, and $1 \%$ BSA and isotope-labeled DNA probes for overnight at $65^{\circ}$ $\mathrm{C}$, followed by washing with $0.5 \times$ SSC and $0.1 \%$ SDS at $65^{\circ} \mathrm{C}$. Region specific DNA probes for $\mathrm{p} 1-\mathrm{p} 5$ regions were generated with PCR (See additional file 9: Table S1. Primers used for this study). The DNA fragments were TAcloned into pGEM-Teasy vector, and the inserted DNA 
was purified from SmaI/XbaI digestion of the plasmid. The probes were labeled with $\left[\alpha-{ }^{32} \mathrm{P}\right] \mathrm{dCTP}$ by BcaBest labelling kit (TAKARA, Japan) according to the manufacture's protocol.

\section{Strand-specific RT-PCR and quantitative RT-PCR}

Primers for RT-PCR are described in the additional file 9. DNaseI-treated RNA samples were reverse-transcribed with Tag-RT-primer at $55^{\circ} \mathrm{C}$ for $50 \mathrm{~min}$ by SuperScript III reverse transcriptase (Invitrogen). Semiquantitative RT-PCR was performed by AccuPrime DNA polymerase (Invitrogen) with the gene-specific primer and Tag primer (See also Figure 2A).

For strand-specific quantification, the cDNAs were analyzed by real-time PCR system (Thermal cycler Dice, TAKARA). The strand-specific quantitative PCR (qPCR) was performed by gene-specific primers and SYBRGreen (TAKARA). Standard curves for strand-specific qRT-PCR at R7 region were generated by linearized plasmids into which target strand-specific RT-PCR products were inserted. Levels of b-actin RNA were measured as internal controls [55].

\section{$3^{\prime}$ and 5' RACE of antisense RNAs}

Both $3^{\prime}$ and 5' RACE methods were performed with 500 ng poly $(\mathrm{A})^{+}$RNA samples according to the manufacturer's protocols ( $3^{\prime}$ - and 5'-Full RACE Core Set, TAKARA). $1^{\text {st }}$ and $2^{\text {nd }}$ PCRs were performed by GeneTaq DNA polymerase (WAKO) with region-specific primers (See additional file 9: Table S1. primers used for this study).

\section{In silico analyses}

Genetyx ver.10 and TFsearch were utilized for the promoter analysis of the HIV-1 asRNAs. For predicting ORFs and polyadenylation signals, the sequence of $A S P-L$ was analysed by ORF Finder and HCpolya.

\section{Reporter gene assays}

Linearized firefly reporter plasmid and the RSVRenilla plasmid were co-transfected into $2 \times 10^{5}$ of Molt-4 cells with by Lipofectamine2000 reagent. At $24 \mathrm{~h}$ post-transfection, cells were harvested and evaluated the promoter activities by measurement of luciferase activities (Dual-Luciferase Reporter Assay System, Promega). Representative results of quadruplicate or triplicate experiments are presented with the mean and S.D. Treatment of TNF- $\alpha(0-10 \mathrm{ng} / \mathrm{ml})$ was performed at $12 \mathrm{~h}$ post-transfection and the cells were incubated for an additional $12 \mathrm{~h}$.

\section{Sub-cellular fractionation}

Cultured cells were washed with PBS and lysed with lysis buffer $(10 \mathrm{mM}$ Tris-HCl, pH7.5, $10 \mathrm{mM} \mathrm{NaCl}, 1.5 \mathrm{mM}$
$\mathrm{MgCl}_{2}, 10 \mathrm{mM}$ Vanadyl Complex, $1 \% \mathrm{NP}-40$ ) on ice for $5 \mathrm{~min}$. After centrifugation in 3,000 rpm for $5 \mathrm{~min}$ at $4 \mathrm{C}^{\circ}$, cytoplasmic supernatant and pelleted nuclei were separated and resuspended in ISOGEN-LS (WAKO) for RNA extraction. Relative antisense and sense strand RNA levels were measured by the strand-specific qRT-PCR method described above and calculated the enrichment of RNA levels in each compartment as below. Distribution of interested RNA was calculated as follows: (\% of enrichment in each fraction $)=($ level of RNA in nuclear or cytoplasmic fraction)/(total levels of RNA in nuclear and cytoplasmic fractions) $\times 100$. The efficiency of the fractionation procedure was confirmed by testing the distributions of $\beta$ actin cytoplasmic RNA and U3 small nucleolar RNA (U3 snoRNA) [49].

\section{Measurement of virus production}

Viral replication was evaluated by measurements of free virions in the culture media with RT assay [60]. Levels of intracellular gag and tat RNAs were measured by qRTPCR as described previously [55]. Proviral loads were measured by PCR with $\mathrm{p} 1 \mathrm{R}$ and $\mathrm{p} 2 \mathrm{~F}$ primers (See additional file 9: Table S1. primers used for this study) from genomic DNA samples isolated by QIAamp DNA Blood Mini Kit (Qiagen). Albumin DNA levels were used as a loading control [55].

\section{Retroviral transduction and strand-specific RNA interference}

Recombinant retroviruses carrying shRNA\#1 and \#2 were constructed by annealed double-strand oligonucleotides (shRNA\#1, 5'-GCAAGTTAgCgGCAtTATTCTCGAAAGAATAGTGCTGTTAACTTGC-3'; $\quad$ shRNA\#2, 5' GGTGtTACTCtTAgTGGTTCACGAATGAACCATTAGGAGTAGCACC-3') into a pSIN-sihU6 vector (TAKARA). The sequence of scrambled RNA and detailed procedure of retroviral production were as described previously [55]. After transduction of recombinant viruses and G418 selection, cells were expanded and inoculated with $\mathrm{HIV}_{\mathrm{NL4} 43}$ at $\mathrm{MOI}=0.1$. After 24 hours of viral attachment, cells were washed with PBS and then cultured in a 12-well culture plate.

To confirm the strand-specific knockdown by shRNAs, the cells were transfected with pMIR-REPORT (empty plasmid, Ambion), pMIR-sense $A S P-L$ or pMIR-AS ASP$L$, respectively. These reporters include sense or antisense HIV-1 sequence in the 3 'UTR of luciferase gene.

\section{Additional files}

Additional file 1: Figure S1. Determination of transcript III-iii. (A)

Results of 3' RACE. Top panel summarizes the results. Agarose gel

electrophoresis of 3' RACE PCR products is shown in Figure 3B. The

results of the sequence analyses are shown in the bottom panel. 
Bars and arrows indicate the identified termination sites. The bold arrow shows the major transcript. The upper case letters and arrows in the sequence indicate the termination sites of transcript III-iii. (B) Termination positions of transcript III-iii described in the context of pME18S-asHIV.

\section{Additional file 2: Figure S2. Detection of spliced HIV-1 antisense} RNAs. (A) A map of primer pairs at R11 and R12. (B-C) Results of agarose gel electrophoresis of antisense-specific RT-PCR products at R11 (B) and R12 (C). Expected PCR products derived from spliced transcripts were approximately $2 \mathrm{~kb}$ (B) and $400 \mathrm{bp}$ (C), respectively (indicated by asterisks in lane 2), which are shorter than that of full-length (6 kb at R11 and $5 \mathrm{~kb}$ at R12). Experiments were performed using total RNAs from HEK293T with pME-18 S-asHIV (293 T-asHIV) (left panel) and HIV-1-infected MAGIC-5A (right panel). Lane 1 and 7, cells transfected with a mock vector or no infection control; Lane 2 and 8, cells with pME18S-asHIV or HIV-1 infection; Lane 3 and 9, no RTase control; Lane 4 and 10, no RT primer control; Lane 5 and 11, PCR products with conventional primer pairs with CDNA samples synthesized by random primers; Lane 6 and 12, positive control (amplified from pME18S-asHIV plasmid DNA, or from pNL4-3 plasmid DNA); M, 100 bp marker; $\lambda, \lambda$ Hind III marker.

\section{Additional file 3: Figure S3. HIV-1 antisense RNA pattern in infected} cells. MAGIC-5A cells were infected with HIV-1 ${ }_{\text {NL4-3 }}$ and then analyzed antisense RNAs by antisense-specific RT-PCR at regions R9 (for original ASP $m R N A$ ) and R10 (for ASP-L). Representative results $(n=4)$ were shown. ASP-L was mainly detected. Lanes 1-6 are the same as in Figure 2B.

Additional file 4: Figure S4. Transcriptional activation of HIV-1 antisense RNAs by TNF-a treatment. ACH-2 was treated with TNF-a $(10 \mathrm{ng} / \mathrm{mL}$ ) for $24 \mathrm{~h}$. Total RNAs were extracted and analyzed by strandspecific $\mathrm{QRT}$-PCR at R7. The asterisks denote statistical significance relative to the untreated control $(p<0.02)$.

\section{Additional file 5: Figure S5. Sub-cellular localization of HIV-1} antisense RNAs in the HIV-1 infected T cell lines. Results of subcellular localization analysis of T-cell lines. RNA samples were prepared from cytoplasmic and nuclear fractions of $\mathrm{ACH}-2$ cells and $\mathrm{HIV}^{-1} \mathrm{NL}_{\mathrm{N}-3}$-infected Molt-4 cells as described in the text.

Additional file 6: Figure S6. Sub-cellular localization of $A S P-L$ in the Molt-4 cells stably expressing ASP-L. RNA samples were prepared from cytoplasmic and nuclear fractions of Clone $3 \mathrm{G} 9$ cells. Results of the quantitative measurement of RT-PCR at R7 are presented from CDNAs synthesized with random primers. Fractionation efficiencies were confirmed by measuring the levels of $\beta$-actin cytoplasmic RNA and nuclear U3 snoRNA.

Additional file 7: Figure S7. Inhibitory effects of full-length ASP-L RNA on HIV-1 replication. (A) ASP-L mutants. ASP-L $3^{\prime}$ is a portion of ASP- $L$ bearing the ASP-coding region. ASP-LATG Contains an $\mathrm{A}$ to T mutation at the start codon of ASP. ASP-L $L_{\text {-stop }}$ contains a $C$ to $A$ mutation at the seventh codon of ASP to convert Cysteine into a stop codon. Detailed sequences are provided in the right panels. Upper cases in the nucleotide sequences show the mutated sites. (B-C) Effects of ASP on HIV-1 replication. (B) Expression levels of ASP-L3' measured by qRT-PCR at R7. mock, Clone 2B3 with the empty vector; $w t$, Clone $3 \mathrm{C} 2$ stably expressing wild type ASP-L (Figure 7D-G); C9F and C5D, established Molt-4 clones that stably express ASP-L3'; Molt4, uninfected Molt-4 cells; Molt4-HIV, HIV-1 $1_{N-4-3}$

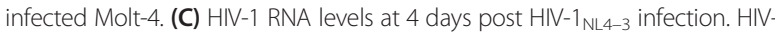
1 RNA levels were evaluated by qRT-PCR with gag and tat genes (mean $\pm S$. D). (D) Effects of ASP-L RNA on HIV-1 replication. $50 \mathrm{ng}$ or $200 \mathrm{ng}$ of plRES-

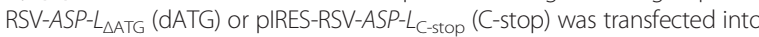

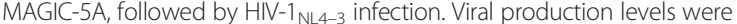
evaluated by RT assays with the supernatants at $72 \mathrm{~h}$ post-transfection. (E) HIV-1 gag RNA levels at $48 \mathrm{~h}$ post-transfection measured by qRT-PCR.'mock' stands for MAGIC-5A with empty vector. 'Wt' stands for MAGIC-5A with pIRES-RSV-ASP-L.

Additional file 8: Supplemental materials and methods. Supplemental materials and methods for expression vectors in Figure S7 are described.

\section{Additional file 9: Table S1. Primers used for this study.}

\section{Abbreviations}

asRNA: antisense RNA; HIV-1: Human immunodeficiency virus type 1; HTLV1: Human T-cell leukemia virus type 1; HBZ: HTLV-1 b-ZIP protein; LTR: Long terminal repeat; PBMCs: Peripheral Blood Mononuclear Cells; PBS: Phosphate- buffered saline; PHA-P: Phytohemagglutinin-P; Tat: Trans-activator of transcription; TNF-a: Tumor necrosis factor-a.

\section{Competing interests}

The authors declare that they have no competing interests.

\section{Acknowledgements}

We gratefully appreciate for Dr. Aya Misawa, and Ms. Erica Yoshida and Mr. Tomohiro Inoue for many useful comments and help.

Grant support: Grants-in-Aid from the Ministry of Health, Labor and Welfare to TW (H19-AIDS-I-003, H22-AIDS-I-002 and H24-AIDS-008).

\section{Author details}

'Laboratory of Tumor Cell Biology, Department of Medical Genome Sciences, Graduate School of Frontier Sciences, The University of Tokyo, 4-6-1 Shirokanedai, Minato-ku, Tokyo 1088639, Japan. ${ }^{2}$ Department of Microbiology, Institute of Health Biosciences, University of Tokushima Graduate School, Kuramoto-cho, Tokushima 7708503, Japan. ${ }^{3}$ Research Center for Asian Infectious Disease, Institute of Medical Science, The University of Tokyo, 4-6-1 Shirokanedai, Minato-ku, Tokyo 1088639, Japan.

\section{Authors' contributions}

MKI improved the strand-specific RT-PCR and carried out most of the experiments and drafted the manuscript. MY advised the experimental designs and helped in drafting and finalizing the manuscripts. TH and YM helped isolate PBMC and extract cellular RNAs. RT advised the protocol used in this study and helped subcloning of shRNA-expression vectors. AM, KN, TY and TI advised the experimental design and protocols used in this study. TW conceived the study, designed the experiments and helped in drafting and finalizing the manuscripts. All authors read and approved the final manuscript.

Received: 13 May 2011 Accepted: 8 May 2012

Published: 8 May 2012

\section{References}

1. Tasara T, Hottiger MO, Hubscher U: Functional genomics in HIV-1 virus replication: protein-protein interactions as a basis for recruiting the host cell machinery for viral propagation. Biol Chem 2001, 382(7):993-999.

2. Trkola A: HIV-host interactions: vital to the virus and key to its inhibition. Curr Opin Microbiol 2004, 7(4):407-411.

3. Fanales-Belasio E, Raimondo M, Suligoi B, Butto S: HIV virology and pathogenetic mechanisms of infection: a brief overview. Ann Ist Super Sanita 2010, 46(1):5-14.

4. Van Lint C, Emiliani S, Ott M, Verdin E: Transcriptional activation and chromatin remodeling of the HIV-1 promoter in response to histone acetylation. EMBO J 1996, 15(5):1112-1120.

5. Bennasser $Y$, Yeung ML, Jeang KT: HIV-1 TAR RNA subverts RNA interference in transfected cells through sequestration of TAR RNA-binding protein, TRBP. J Biol Chem 2006, 281(38):27674-27678

6. Colin L, Van Lint C: Molecular control of HIV-1 postintegration latency: implications for the development of new therapeutic strategies. Retrovirology 2009, 6:111.

7. Miller RH: Human immunodeficiency virus may encode a novel protein on the genomic DNA plus strand. Science 1988, 239(4846):1420-1422.

8. Michael NL, Vahey MT, d'Arcy L, Ehrenberg PK, Mosca JD, Rappaport J, Redfield RR: Negative-strand RNA transcripts are produced in human immunodeficiency virus type 1-infected cells and patients by a novel promoter downregulated by Tat. J Virol 1994, 68(2):979-987.

9. Vanhee-Brossollet C, Thoreau H, Serpente N, D'Auriol L, Levy JP, Vaquero C: A natural antisense RNA derived from the HIV-1 env gene encodes a protein which is recognized by circulating antibodies of HIV + individuals. Virology 1995, 206(1):196-202.

10. Ludwig LB, Ambrus JL Jr, Krawczyk KA, Sharma S, Brooks S, Hsiao CB, Schwartz SA: Human Immunodeficiency Virus-Type 1 LTR DNA contains an intrinsic gene producing antisense RNA and protein products. Retrovirology 2006, 3:80.

11. Landry S, Halin M, Lefort S, Audet B, Vaquero C, Mesnard JM, Barbeau B: Detection, characterization and regulation of antisense transcripts in HIV-1. Retrovirology 2007, 4:71. 
12. Peeters A, Lambert PF, Deacon NJ: A fourth Sp1 site in the human immunodeficiency virus type 1 long terminal repeat is essential for negative-sense transcription. J Virol 1996, 70(10):6665-6672.

13. Tagieva NE, Vaquero C: Expression of naturally occurring antisense RNA inhibits human immunodeficiency virus type 1 heterologous strain replication. J Gen Virol 1997, 78(Pt 10):2503-2511.

14. Briquet $S$, Vaquero $C:$ Immunolocalization studies of an antisense protein in HIV-1-infected cells and viral particles. Virology 2002, 292(2):177-184.

15. Bentley K, Deacon N, Sonza S, Zeichner S, Churchill M: Mutational analysis of the HIV-1 LTR as a promoter of negative sense transcription. Arch Virol 2004, 149(12):2277-2294.

16. Bansal A, Carlson J, Yan J, Akinsiku OT, Schaefer M, Sabbaj S, Bet A, Levy DN, Heath S, Tang J, Kaslow RA, Walker BD, Ndung'U T, Goulder PJ, Heckerman D, Hunter E, Goepfert PA: CD8 T cell response and evolutionary pressure to HIV-1 cryptic epitopes derived from antisense transcription. J Exp Med 2010, 207(1):51-59.

17. Yeung $M L$, Bennasser $Y$, Watashi $K$, Le SY, Houzet $L$, Jeang $K T$ : Pyrosequencing of small non-coding RNAs in HIV-1 infected cells: evidence for the processing of a viral-cellular double-stranded RNA hybrid. Nucleic Acids Res 2009, 37(19):6575-6586.

18. Lefebvre G, Desfarges S, Uyttebroeck F, Munoz M, Beerenwinkel N, Rougemont J, Telenti A, Ciuffi A: Analysis of HIV-1 expression level and sense of transcription by high-throughput sequencing of the infected cell. J Virol 2011, 85(13):6205-6211.

19. ClerC I, Laverdure S, Torresilla C, Landry S, Borel S, Vargas A, Arpin-Andre C, Gay B, Briant L, Gross A, Barbeau B, Mesnard JM: Polarized expression of the membrane ASP protein derived from HIV-1 antisense transcription in T cells. Retrovirology 2011, 8:74.

20. Schopman NC, Willemsen M, Liu YP, Bradley T, van Kampen A, Baas F, Berkhout B, Haasnoot J: Deep sequencing of virus-infected cells reveals HIV-encoded small RNAs. Nucleic Acids Res 2012, 40(1):414-427.

21. Larocca D, Chao LA, Seto MH, Brunck TK: Human T-cell leukemia virus minus strand transcription in infected T-cells. Biochem Biophys Res Commun 1989, 163(2):1006-1013.

22. Gaudray G, Gachon F, Basbous J, Biard-Piechaczyk M, Devaux C, Mesnard JM: The complementary strand of the human T-cell leukemia virus type 1 RNA genome encodes a bZIP transcription factor that down-regulates viral transcription. J Virol 2002, 76(24):12813-12822.

23. Cavanagh MH, Landry S, Audet B, Arpin-Andre C, Hivin P, Pare ME, Thete J, Wattel E, Marriott SJ, Mesnard JM, Barbeau B: HTLV-I antisense transcripts initiating in the 3 'LTR are alternatively spliced and polyadenylated. Retrovirology 2006, 3:15.

24. Satou Y, Yasunaga J, Yoshida M, Matsuoka M: HTLV-I basic leucine zipper factor gene mRNA supports proliferation of adult T cell leukemia cells. Proc Natl Acad Sci U S A 2006, 103(3):720-725.

25. Arnold J, Zimmerman B, Li M, Lairmore MD, Green PL: Human T-cell leukemia virus type-1 antisense-encoded gene, $\mathrm{Hbz}$, promotes $\mathrm{T}$ lymphocyte proliferation. Blood 2008, 112(9):3788-3797.

26. Matsuoka M, Green PL: The HBZ gene, a key player in HTLV-1 pathogenesis. Retrovirology 2009, 6:71

27. Briquet S, Richardson J, Vanhee-Brossollet C, Vaquero C: Natural antisense transcripts are detected in different cell lines and tissues of cats infected with feline immunodeficiency virus. Gene 2001, 267(2):157-164.

28. Rasmussen MH, Ballarin-Gonzalez B, Liu J, Lassen LB, Fuchtbauer A, Fuchtbauer EM, Nielsen AL, Pedersen FS: Antisense transcription in gammaretroviruses as a mechanism of insertional activation of host genes. J Virol 2010, 84(8):3780-3788.

29. Matsuda E, Garfinkel DJ: Posttranslational interference of Ty1 retrotransposition by antisense RNAs. Proc Natl Acad Sci U S A 2009, 106(37):15657-15662.

30. Sasaki YT, Ideue T, Sano M, Mituyama T, Hirose T: MENepsilon/beta noncoding RNAs are essential for structural integrity of nuclear paraspeckles. Proc Natl Acad Sci U S A 2009, 106(8):2525-2530.

31. Katayama S, Tomaru Y, Kasukawa T, Waki K, Nakanishi M, Nakamura M, Nishida H, Yap CC, Suzuki M, Kawai J, Suzuki H, Carninci P, Hayashizaki Y, Wells C, Frith M, Ravasi T, Pang KC, Hallinan J, Mattick J, Hume DA, Lipovich L, Batalov S, Engstrom PG, Mizuno Y, Faghihi MA, Sandelin A, Chalk AM, Mottagui-Tabar S, Liang Z, Lenhard B, Wahlestedt C, RIKEN Genome Exploration Research Group, Genome Science Group (Genome Network Project Core Group), FANTOM Consortium: Antisense transcription in the mammalian transcriptome. Science 2005, 309(5740):1564-1566.
32. Wagner EG, Altuvia S, Romby P: Antisense RNAs in bacteria and their genetic elements. Adv Genet 2002, 46:361-398.

33. Georg J, Honsel A, Voss B, Rennenberg H, Hess WR: A long antisense RNA in plant chloroplasts. New Phytol 2010, 186(3):615-622.

34. Unver T, Bakar M, Shearman RC, Budak H: Genome-wide profiling and analysis of Festuca arundinacea miRNAs and transcriptomes in response to foliar glyphosate application. Mol Genet Genomics 2010, 283(4):397-413.

35. Lyle R, Watanabe D, te Vruchte D, Lerchner W, Smrzka OW, Wutz A, Schageman J, Hahner L, Davies C, Barlow DP: The imprinted antisense RNA at the Igf2r locus overlaps but does not imprint Mas1. Nat Genet 2000, 25(1):19-21.

36. Zhao J, Sun BK, Erwin JA, Song JJ, Lee JT: Polycomb proteins targeted by a short repeat RNA to the mouse $\mathrm{X}$ chromosome. Science 2008, 322(5902):750-756.

37. Faghihi MA, Modarresi F, Khalil AM, Wood DE, Sahagan BG, Morgan $T E$, Finch CE, St Laurent G 3rd, Kenny PJ, Wahlestedt C: Expression of a noncoding RNA is elevated in Alzheimer's disease and drives rapid feed-forward regulation of beta-secretase. Nat Med 2008, 14(7):723-730.

38. Faghihi MA, Wahlestedt C: Regulatory roles of natural antisense transcripts. Nat Rev Mol Cell Biol 2009, 10(9):637-643.

39. Gupta RA, Shah N, Wang KC, Kim J, Horlings HM, Wong DJ, Tsai MC, Hung T, Argani P, Rinn JL, Wang Y, Brzoska P, Kong B, Li R, West RB, van de Vijver MJ, Sukumar S, Chang HY: Long non-coding RNA HOTAIR reprograms chromatin state to promote cancer metastasis. Nature 2010, 464(7291):1071-1076.

40. Yap KL, Li S, Munoz-Cabello AM, Raguz S, Zeng L, Mujtaba S, Gil J, Walsh MJ, Zhou MM: Molecular interplay of the noncoding RNA ANRIL and methylated histone $\mathrm{H} 3$ lysine 27 by polycomb CBX7 in transcriptional silencing of INK4a. Mol Cell 2010, 38(5):662-674.

41. Tufarelli C, Stanley JA, Garrick D, Sharpe JA, Ayyub H, Wood WG, Higgs DR: Transcription of antisense RNA leading to gene silencing and methylation as a novel cause of human genetic disease. Nat Genet 2003, 34(2):157-165

42. Luther HP: Role of endogenous antisense RNA in cardiac gene regulation. J Mol Med 2005, 83(1):26-32.

43. Haddad F, Qin AX, Giger JM, Guo H, Baldwin KM: Potential pitfalls in the accuracy of analysis of natural sense-antisense RNA pairs by reverse transcription-PCR. BMC Biotechnol 2007, 7:21.

44. Hachiya A, Aizawa-Matsuoka S, Tanaka M, Takahashi Y, Ida S, Gatanaga H, Hirabayashi Y, Kojima A, Tatsumi M, Oka S: Rapid and simple phenotypic assay for drug susceptibility of human immunodeficiency virus type 1 using CCR5-expressing HeLa/CD4(+) cell clone 1-10 (MAGIC-5). Antimicrob Agents Chemother 2001, 45(2):495-501.

45. Bell SD, Brinkman AB, van der Oost J, Jackson SP: The archaeal TFIIEalpha homologue facilitates transcription initiation by enhancing TATA-box recognition. EMBO Rep 2001, 2(2):133-138.

46. Bjornsdottir G, Myers LC: Minimal components of the RNA polymerase II transcription apparatus determine the consensus TATA box. Nucleic Acids Res 2008, 36(9):2906-2916.

47. Folks TM, Clouse KA, Justement J, Rabson A, Duh E, Kehrl JH, Fauci AS: Tumor necrosis factor alpha induces expression of human immunodeficiency virus in a chronically infected T-cell clone. Proc Natl Acad Sci U S A 1989, 86(7):2365-2368.

48. Butera ST, Perez VL, Wu BY, Nabel GJ, Folks TM: Oscillation of the human immunodeficiency virus surface receptor is regulated by the state of viral activation in a CD4+ cell model of chronic infection. J Virol 1991, 65(9):4645-4653.

49. Berteaux N, Aptel N, Cathala G, Genton C, Coll J, Daccache A, Spruyt N, Hondermarck H, Dugimont T, Curgy JJ, Forne T, Adriaenssens E: A novel H19 antisense RNA overexpressed in breast cancer contributes to paternal IGF2 expression. Mol Cell Biol 2008, 28(22):6731-6745.

50. van der Sluis RM, Pollakis G, van Gerven ML, Berkhout B, Jeeninga RE: Latency profiles of full length HIV-1 molecular clone variants with a subtype specific promoter. Retrovirology 2011, 8:73.

51. Kilareski EM, Shah S, Nonnemacher MR, Wigdahl B: Regulation of HIV-1 transcription in cells of the monocyte-macrophage lineage. Retrovirology 2009, 6:118.

52. Ohhata T, Hoki Y, Sasaki H, Sado T: Crucial role of antisense transcription across the Xist promoter in Tsix-mediated Xist chromatin modification. Development 2008, 135(2):227-235. 
53. Adachi A, Gendelman HE, Koenig S, Folks T, Willey R, Rabson A, Martin MA: Production of acquired immunodeficiency syndrome-associated retrovirus in human and nonhuman cells transfected with an infectious molecular clone. J Virol 1986, 59(2):284-291.

54. Takebe Y, Seiki M, Fujisawa J, Hoy P, Yokota K, Arai K, Yoshida M, Arai N: SR alpha promoter: an efficient and versatile mammalian CDNA expression system composed of the simian virus 40 early promoter and the R-U5 segment of human T-cell leukemia virus type 1 long terminal repeat. Mol Cell Biol 1988, 8(1):466-472.

55. Yamagishi M, Ishida T, Miyake A, Cooper DA, Kelleher AD, Suzuki K, Watanabe T: Retroviral delivery of promoter-targeted shRNA induces long-term silencing of HIV-1 transcription. Microbes Infect 2009, 11(4):500-508.

56. Barik S: Site-directed mutagenesis by double polymerase chain reaction: megaprimer method. Methods Mol Biol 1993, 15:277-286.

57. Yamochi T, Yamochi T, Aytac U, Sato T, Sato K, Ohnuma K, McKee KS, Morimoto C, Dang NH: Regulation of p38 phosphorylation and topoisomerase llalpha expression in the B-cell lymphoma line Jiyoye by CD26/dipeptidyl peptidase IV is associated with enhanced in vitro and in vivo sensitivity to doxorubicin. Cancer Res 2005, 65(5):1973-1983.

58. Miyake A, Ishida T, Yamagishi M, Hara T, Umezawa K, Watanabe T, Horie R: Inhibition of active HIV-1 replication by NF-kappaB inhibitor DHMEQ. Microbes Infect 2010, 12(5):400-408.

59. Ishida T, Hamano A, Koiwa T, Watanabe T: 5' long terminal repeat (LTR)-selective methylation of latently infected HIV-1 provirus that is demethylated by reactivation signals. Retrovirology 2006, 3:69.

60. Willey RL, Smith DH, Lasky LA, Theodore TS, Earl PL, Moss B, Capon DJ, Martin MA: In vitro mutagenesis identifies a region within the envelope gene of the human immunodeficiency virus that is critical for infectivity. J Virol 1988, 62(1):139-147.

doi:10.1186/1742-4690-9-38

Cite this article as: Kobayashi-lshihara et al: HIV-1-encoded antisense RNA suppresses viral replication for a prolonged period. Retrovirology 2012 9:38.

\section{Submit your next manuscript to BioMed Central and take full advantage of:}

- Convenient online submission

- Thorough peer review

- No space constraints or color figure charges

- Immediate publication on acceptance

- Inclusion in PubMed, CAS, Scopus and Google Scholar

- Research which is freely available for redistribution 